\title{
Natural Gas Contracts in Efficient Portfolios
}

by Ronald J. Sutherland*

Policy and Economic Analysis Group,

Decision and Information Sciences Division,

Argonne National Laboratory, 9700 South Cass Avenue, Argonne, Illinois 60439

\section{December 1994}

Work sponsored by the U.S. Department of Energy, Assistant Secretary, Office of Policy. This report is the product of a collaborative effort between the U.S. Department of Energy and the Public Service Commission of the State of Maryland.

*Sutherland is located at 955 L'Enfant Plaza, Suite 6000, Washington, D.C. 20024.

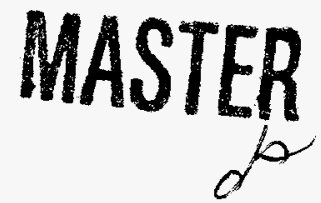




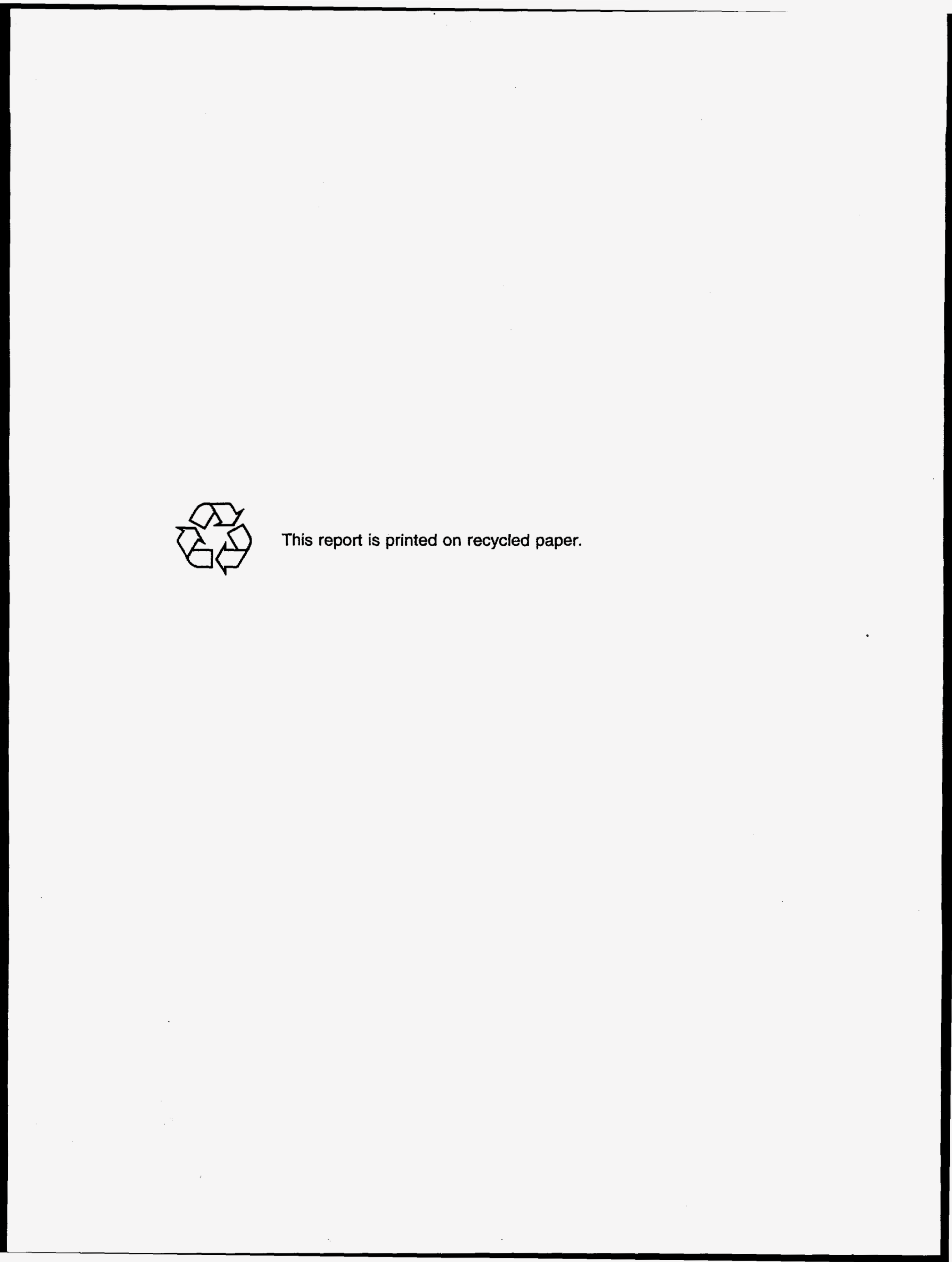




\section{DISCLAIMER}

This report was prepared as an account of work sponsored by an agency of the United States Government. Neither the United States Government nor any agency thereof, nor any of their employees, make any warranty, express or implied, or assumes any legal liability or responsibility for the accuracy, completeness, or usefulness of any information, apparatus, product, or process disclosed, or represents that its use would not infringe privately owned rights. Reference herein to any specific commercial product, process, or service by trade name, trademark, manufacturer, or otherwise does not necessarily constitute or imply its endorsement, recommendation, or favoring by the United States Government or any agency thereof. The views and opinions of authors expressed herein do not necessarily state or reflect those of the United States Government or any agency thereof. 


\section{DISCLAIMER}

Portions of this document may be illegible in electronic image products. Images are produced from the best available original document. 


\section{CONTENTS}

ACKNOWLEDGMENTS $\ldots \ldots \ldots \ldots \ldots \ldots \ldots \ldots \ldots \ldots \ldots \ldots \ldots \ldots \ldots$

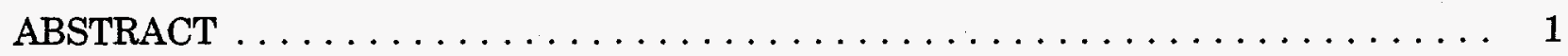

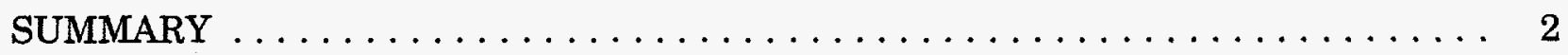

1 INTRODUCTION $\ldots \ldots \ldots \ldots \ldots \ldots \ldots \ldots \ldots \ldots \ldots \ldots \ldots \ldots \ldots$

2 OVERVIEW OF THE GAS SUPPLY INDUSTRY $\ldots \ldots \ldots \ldots \ldots \ldots$

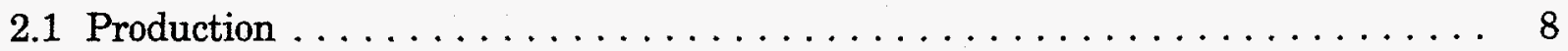

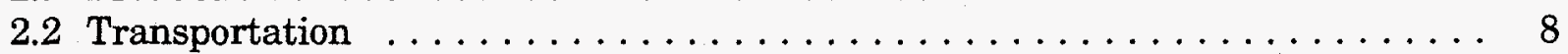

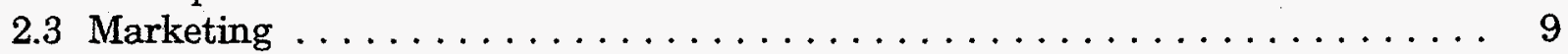

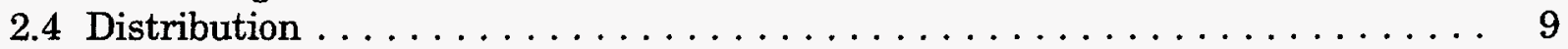

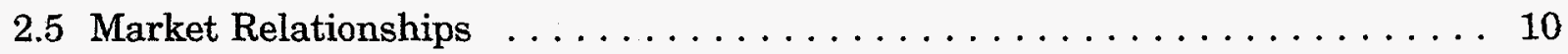

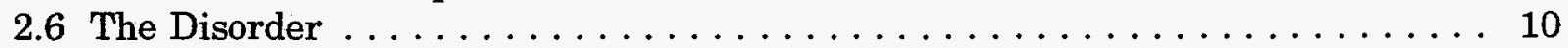

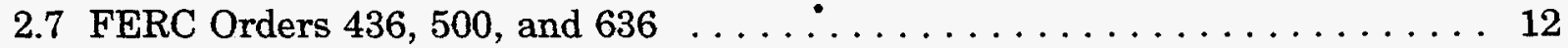

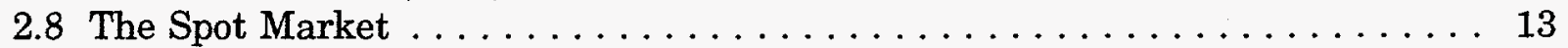

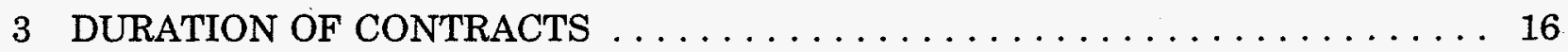

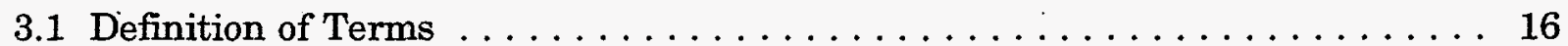

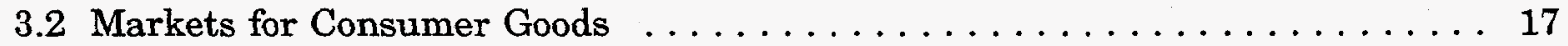

3.3 Contract Duration . . . . . . . . . . . . . . . . . . . . . 19

4 THE FUTURES MARKET $\ldots \ldots \ldots \ldots \ldots \ldots \ldots \ldots \ldots \ldots \ldots$

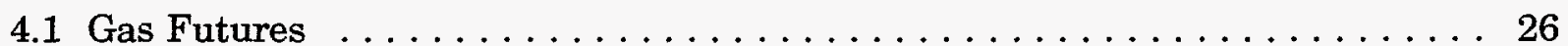

4.2 Price Discovery . . . . . . . . . . . . . . . . . . . 27

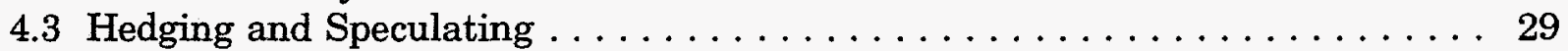

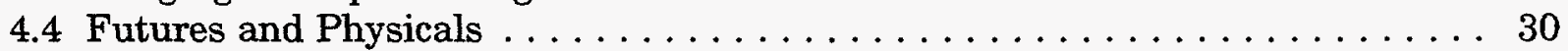

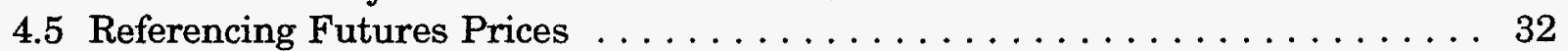

5 GAS CONTRACTS IN EFFICIENT PORTFOLIOS $\ldots \ldots \ldots \ldots \ldots \ldots \ldots$

5.1 The Contract Problem $\ldots \ldots \ldots \ldots \ldots \ldots \ldots \ldots \ldots \ldots \ldots \ldots \ldots$

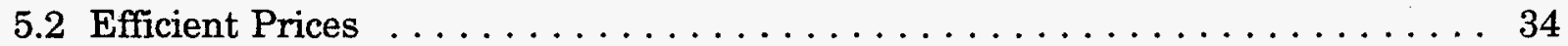

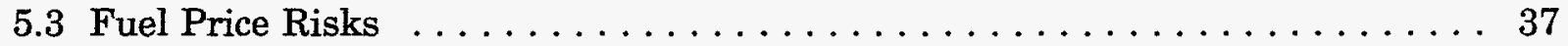

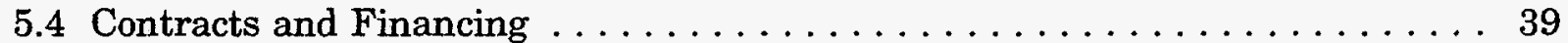

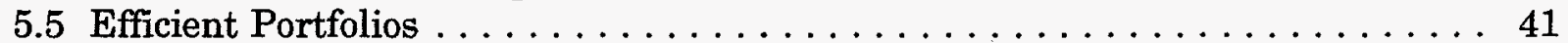

6 CONTRACTS WITH REGULATED UTILITIES $\ldots \ldots \ldots \ldots \ldots \ldots \ldots \ldots \ldots$

6.1 The Principal Agent Problem $\ldots \ldots \ldots \ldots \ldots \ldots \ldots \ldots \ldots \ldots \ldots \ldots$

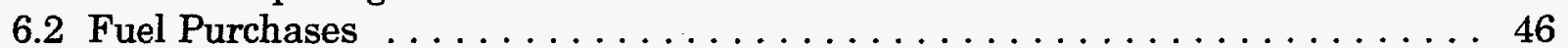

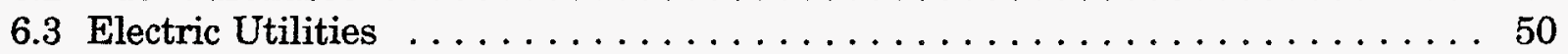


CONTENTS (Cont.)

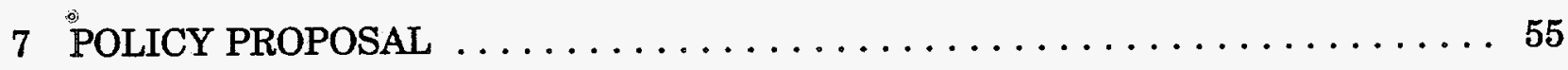

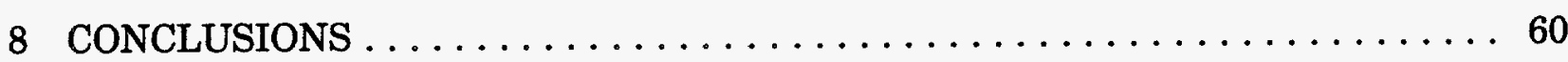

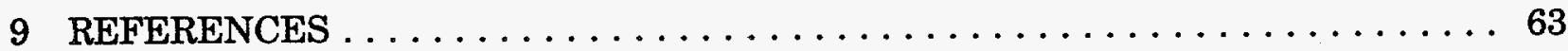

TABLE

1 Estimated U.S. Spot Market Volume $\ldots \ldots \ldots \ldots \ldots \ldots \ldots \ldots \ldots \ldots \ldots$

\section{FIGURES}

1 Traditional and Present Gas Märkets $\ldots \ldots \ldots \ldots \ldots \ldots \ldots \ldots \ldots \ldots \ldots \ldots$

2 Natural Gas Transported as Sales and Carriage for Market ............ 13

3 Relationship between Transaction Costs and Contract Durations ........... 22

4 Market Prices and Fixed Prices for Natural Gas in a Three-Year Period . . . . . 36 


\section{ACKNOWLEDGMENTS}

This study has benefitted from the helpful comments of Kenneth Malloy, Rodney Lemon, Donald Rosenthal, Glenn Clark, Russel Profozich, John Herbert, Michael York, Ned Dearborn, R. Skip Horvath, Kenneth Costello, and Michael Giberson, and from our working group with the Public Service Commission of the State of Maryland. 


\title{
NATURAL GAS CONTRACTS IN EFFICIENT PORTFOLIOS
}

by

\author{
Ronald J. Sutherland
}

\begin{abstract}
This report addresses the "contracts portfolio" issue of natural gas contracts in support of the Domestic Natural Gas and Oil Initiative (DGOI) published by the U.S. Department of Energy in 1994. The analysis is a result of a collaborative effort with the Public Service Commission of the State of Maryland to consider "reforms that enhance the industry's competitiveness" (DGOI, p. 22). The initial focus of our collaborative effort was on gas purchasing and contract portfolios; however, it became apparent that efficient contracting to purchase and use gas requires a broader consideration of regulatory reform. Efficient portfolios are obtained when the holder of the portfolio is affected by and is responsible for the performance of the portfolio. Natural gas distribution companies may prefer a diversity of contracts, but the efficient use of gas requires that the local distribution company be held accountable for its own purchases. Ultimate customers are affected by their own portfolios, which they manage efficiently by making their own choices. The objectives of the DGOI, particularly the efficient use of gas, can be achieved when customers have access to suppliers of gas and energy services under an improved regulatory framework.
\end{abstract}

The evolution of the natural gas market during the last 15 years is described to account for the changing preferences toward gas contracts. Long-term contracts for natural gas were prevalent before the early 1980 s, primarily because gas producers had few options other than to sell to a single pipeline company, and this pipeline company, in turn, was the only seller to a gas distribution company. During the mid-1980s, however, as pipeline companies became contract carriers, there were opportunities for many buyers to transact business with many sellers, and the need for longterm contracts diminished. Spot and futures markets developed, resulting in a widespread knowledge of current market prices that has facilitated contracting at these prices.

The intense debate about long-term fixed-price contracts is not actually about contracts, but regulatory approval of these contracts. As state commissions show diminished interest in such contracts, the market will tend to disappear. Other issues are emerging, such as purchasing gas at a premium and local distribution company participation in the futures 
market. Like gas contract issues, the controversy is not about premiums or futures market participation, but about regulatory approval of such actions. A more competitive gas distribution system at the local level would resolve these issues along with gas contract issues.

\section{SUMMARY}

The Domestic Natural Gas and Oil Initiative (DGOI) of the U.S. Department of Energy (DOE) emphasizes the efficient pricing of gas and electricity and the use of portfolios of natural gas contracts by distribution companies and end users (DOE 1994). One purpose of this study is to define the terms of contracts contained in efficient portfolios of ultimate customers and local distribution companies. The DGOI further states that the DOE will undertake collaborative efforts with states to support regulatory reforms that will enhance the competitiveness of the industry. This report on contracts is in support of the first DOE collaborative effort, which is with the Public Service Commission of the State of Maryland. Although the report is a lengthy technical analysis of the efficient contracting for gas, the main conclusion is that contract issues can only be resolved by creating a more competitive market.

In this study, the duration and price components of natural gas contracts are analyzed separately. Contract duration is discussed in the technical literature that emphasizes using contracts to minimize transaction costs. In a market structure in which only a few buyers deal with a few sellers, long-term contracts are generally used to minimize transaction costs. In contrast, in a market structure with a large number of buyers and sellers, spot purchases result in lower transaction costs than long-term contracts. With the unbundling of gas transportation services and the development of contract carriage, the gas market has evolved to one in which numerous buyers can do business with numerous sellers, and this business is conducted efficiently and reliability with short-term contracts.

Contracts may specify that future gas transactions be conducted at market prices referenced to the spot or futures market, or at prices that differ from these market prices. The choice to contract at market-based prices or fixed prices depends on a number of factors, such as risk preferences, the principal agent problem, and the availability of information on current market prices. In general, contracts tend to reflect market prices when such prices are used for current transactions. When market prices do not exist or are not widely known (as in the case of regulated markets), contracts are likely to specify nonmarket prices. The recent development of the spot market and futures market for gas contracts has facilitated and encouraged the use of spot and futures prices in gas transactions.

Wellhead price decontrol (beginning in 1978) allowed market forces to be reflected in gas prices. Federal Energy Regulatory Commission (FERC) Orders 436 and 500 resulted in the open access of natural gas pipelines, which enabled producers to sell directly to large customers. The market developed from one in which producers had access to a single buyer to one in which producers have access to numerous customers. Customers, in turn, have 
access to numerous producers instead of a single seller. Before the early 1980 s, long-term contracts may have contributed to a stable business relationship between buyers and sellers. This relationship is now achieved more efficiently by a competitive market. In the current market, long-term contracts at fixed prices have lost much of their transaction cost advantage over short-term contracts and spot purchases. Reliable supplies of natural gas for the long term are now ensured by a large number of producers willing to sell gas on the spot to any buyer. Natural gas supplies can be reliably secured over the long term by successive spot purchases or contracts of various duration, in which the contract price is market based, perhaps by being referenced to futures prices or the spot market. Although efficient portfolios of contracts may include contracts with forward prices, such portfolios are unlikely to emphasize 10- or 20-year fixed-price contracts.

The history of the gas industry reveals that long-term contracts for purchases or sales were required to secure financing for large capital investments (e.g., gas wells, pipelines, and generating plants). In a competitive natural gas market - with its numerous participants - long-term purchases or sales at competitive prices are ensured by market forces, not long-term contracts. The value of long-term fixed-price contracts in obtaining financing for investments in the gas industry has greatly diminished. Indeed, the value of fixed-price contracts derives more from regulatory approval than from any inherent efficiency.

Open access and wellhead price decontrol have encouraged the development of a spot market for gas and then a gas futures market. In the spot market, numerous buyers contract with numerous sellers for short-term delivery. In the futures market, efficient prices are discovered and conveyed to any participant in the gas market. Futures prices in most industries are the standard reference price for exchange. In the gas industry, futures prices and spot-market prices are the frequent reference price for transactions. Prior to the development of spot markets, fixed-price contracts for gas were preferred because a competitive market price could not be easily ascertained. However, since the development of numerous regional spot markets and the gas futures market, a competitive market price is available to anyone who reads a major daily newspaper. The publication of widely available current market prices makes contracting for gas at fixed or non-market-based prices less efficient and less tenable.

State utility commissioners have a keen interest in understanding gas contract issues and deciding on the types of contracts to allow under current regulations. The recommendation of this study is that customers have the opportunity to make choices for their own portfolios. In addition, we note an inherent - but rapidly disappearing - bias in regulation toward long-term contracts at relatively fixed prices. Such contracts may appear to provide more reliability and stability than they actually provide, and they may not reflect the preferences of customers. In particular, regulated utilities may have an incentive to reduce price variability (the principal agent problem), and such price stability might not be in the interests of their customers.

A goal of energy policy, expressed in the DGOI, is to obtain efficient pricing for natural gas. This goal is attained by market conditions under which the price of gas reflects 
its true economic value. Efficiency in the gas market would be enhanced by the use of market-based prices in gas contracts. Also, the direct access to ultimate customers by thirdparty providers would encourage the use of market-based pricing.

Utilities and their customers have been exposed to two serious risks that have impeded the efficient use of resources. Utilities (especially electric utilities) have made major capital investments with the expectation that they could pass on the costs to ratepayers, and some of these expenses have subsequently been disallowed. The first risk, the risk of disallowance, can distort utility choices and cause inefficiencies. The second risk occurs when utility investments with inefficient outcomes are allowed, and the costs of inefficiency are borne by ratepayers. In a competitive market, the costs of unfortunate business decisions are borne by stockholders and not shifted to customers. To achieve the efficient pricing of gas and eliminate these two risks, the following principle is suggested: All participants in the gas industry - producers, industrial customers, electric and gas utilities, and ultimate customers - should have a menu of choices in gas contracts and be allowed to sign any contracts they prefer, provided that they be held accountable for the contractual terms. The only way that regulators can "allow" gas contract terms to reflect the interest of various participants is to allow these participants to make their own choices and abide by the results.

One of the most controversial issues in the industry is the economic merit of longterm and fixed-price contracts for natural gas. Much of this report is a technical explanation showing that transactions costs are minimized with the use of short-term contracts at spot prices. The relevant policy issue is not the efficiency of various contracts, but their approval by state regulatory commissions. A policy recommendation of this report is to offer the ultimate customers a menu of choices for contract terms and allow them to decide what terms are appropriate for their needs. A range of contract choices could be obtained if the ultimate customers of a local distribution company (LDC) had access to alternative providers of gas. One policy option is to unbundle the services of an LDC and allow gas merchants to sell directly to ultimate customers. If gas merchants had direct access to ultimate customers, the issue of efficient contracts would be resolved by the market. The principal agent problem would no longer exist, and the risk of disallowance would be eliminated. The market failure that justifies regulation of LDCs is the natural monopoly element associated with distributing gas. No market failure exists that requires the purchase of gas by a regulated monopoly.

The interests of ultimate customers are enhanced when they purchase gas at terms appropriate for their own portfolios. In addition, LDCs can sign contracts that are in the interest of the utility or its stockholders. If an LDC believes that a long-term fixed-price contract for gas reflects stockholder or management interests, the utility should have the option to sign such a contract. However, if customers do not show a preference for these contracts, customers should pay current market prices. Also, if a utility wishes to buy gas in the ground, it should be allowed to do so, but only at stockholder risk. The outcome of these investments should be reflected as dividends or losses, not in terms of allowable fuel costs. In this way, utilities would have the opportunity to reflect stockholder interests without the principal agent problem being imposed on customers. 
A more competitive gas distribution market, in which customers and utilities each make their own portfolio decisions, would offer the following advantages:

- The principal agent problem would be eliminated. This problem occurs when utilities have an incentive to make long-term contracts and are willing to pay nonmarket prices (such as fixed prices or a high premium above market prices) because such contracts are thought to ensure supply reliability. Costs at above-market prices are shifted to customers.

- Customers could make appropriate fuel use and technology choices if market-based prices were charged to ultimate customers because the pricing system would be able to send efficient signals.

- Public utility commissions (PUCs) would not have to pass judgment on the efficiency of various contracts, nor would they have to decide on the appropriateness of a price premium or of futures market participation.

- The risks of bad business decisions being shifted to customers would be eliminated.

- The contracts problem, resulting in breach of contract, or in "stranded assets" would be eliminated.

- If ultimate customers prefer to purchase gas at other-than-spot prices, their preferences would be accommodated by the market without regulatory controversy.

- The policy goal stated in the DGOI of encouraging efficient portfolios of contracts would automatically be achieved because customers would choose their own portfolio, instead of having a single LDC portfolio imposed upon all customers.

Allowing increased access to LDC distribution systems by gas merchants has several additional advantages: first, merely the threat of increased competition would encourage increased efficiencies by LDCs; second, customers may obtain lower prices through competitive suppliers; third, customers would see a wider menu of contract choices; and fourth, gas merchants could provide additional services, such as energy conservation.

Allowing open access at the distribution level will not result in all customers obtaining gas from gas merchants; indeed LDCs are likely to continue serving most customers until a more competitive market develops. Some efficiencies would be obtained if (at least a share of) gas were purchased under competitive procurement and the price used as a "yardstick" for direct purchases by LDCs. State utility commissions could impose a price cap referenced to current market prices. An analysis of these options is not part of this report, but is being undertaken as part of our collaborative effort with the Public Service 
Commission of the State of Maryland. Incentive regulatory schemes are inherently limited in terms of producing market outcomes that approximate a competitive market. The only way that competitive results can be achieved is to encourage competition behind the city gate. 


\section{INTRODUCTION}

Natural gas is viewed by many as the fuel of the 1990s and beyond because it is a relatively clean, low-cost, and long-term domestic energy source. However, the regulatory treatment of gas contracts is contentious and has impaired the efficient use of gas for several years. The relationship between supply reliability and contracts is explained here in terms of the number of buyers and sellers in a market. Under appropriate state regulatory policies, utilities could contract for gas and obtain reliable supplies at competitive market prices. Public utility commissions (PUCs) are encouraged to allow ultimate customers the opportunity to select their own contracts; but when utilities purchase, transport and store gas, they should minimize the cost relative to the current market purchase price.

The natural gas market has changed significantly since the early 1980 s in ways that affect contract prices and durations. The conditions that influenced the supply of gas historically were government regulations, pipeline companies that performed the merchant function, long-term contracts, and fixed prices. In contrast, the characteristics of the current gas supply market are reduced government regulation, open pipeline access, and the development of spot and futures markets and short-term and spot-market transactions. This market transformation is described briefly in Section 2 .

There is an important distinction between the duration and price components of a contract. The duration of contracts is explained primarily in terms of "asset specificity" and minimization of transaction costs. Section 3 reviews the literature on contracts to help explain the long-term duration of gas contracts that were written before the early 1980s and the short-term duration of the contracts that are being written now. Historically, the price component of gas contracts was influenced by regulations from the wellhead to the burner tip. Prices set by regulations instead of market forces are highly rigid and such prices encourage contracting at fixed prices. The development of the gas futures market means that market-based prices are discovered and conveyed to all market participants. The natural gas futures market and its implications with respect to gas pricing are discussed in Section 4. The composition of gas contracts in efficient portfolios is discussed in Section 5. Regulatory emphasis is placed on the local distribution company's (LDC's) portfolio; however, this is inappropriate. The portfolio relevant to a residential household is the household's portfolio. The portfolio relevant to a stockholder in an LDC is the stockholder's portfolio. Neither of these portfolios corresponds to the LDC's portfolio of gas contracts. The regulatory process may encourage inefficiencies in gas contracts in the form of fixed prices and long-term contracts. Section 6 is an analysis of the regulatory process and its implications for efficient contracting. A policy proposal is described in Section 7, and conclusions are presented in Section 8. 


\section{OVERVIEW OF THE GAS SUPPLY INDUSTRY}

- This section presents a brief overview of the gas supply industry. The specific objective is to describe the characteristics of the industry that determine the terms of contractual agreements. The most important terms in a contract are its duration and its price component. These terms have been dramatically influenced by characteristics of the industry that have evolved over the last decade or so. This evolution in the supply sector is examined through a description of the industry as it was in about 1980 and again as it is today. The gas supply industry consists of four components: production, marketing, transportation, and distribution.

\subsection{PRODUCTION}

Most of the gas consumed in the United States is produced from domestic gas wells. The marketed production of gas in 1990 was about 18.4 trillion cubic feet (tcf) (DOE 1991a, p. 167). ${ }^{1}$ Although gas is produced in 32 states, a large share is produced in Texas (6.3 tcf in 1990), Louisiana (5.2 tcf), and Oklahoma (2.3 tcf). Of the approximately 270,000 producing gas wells, Texas has more than any other state $(50,867)$, followed by West Virginia $(37,500)$, Ohio (34,586), and Pennsylvania $(30,300)$. The production of gas is widely distributed geographically among a large number of firms. Seven major oil companies are also the seven largest U.S. gas producers and are responsible for about one-thïrd of U.S. output. However, the remaining two-thirds of domestic gas is produced by other large independent producers and more than 10,000 small independent producers. A decade ago, the largest 20 producers owned $46 \%$ of all reserves. Today, the largest 20 control 53\%. Smaller independent producers have been more affected than the major producers by the downturn in gas prices since the early 1980s. Yet, entry into this industry for onshore exploration and development is still relatively easy. The important characteristic of the production side is the fact that numerous participants compete.

\subsection{TRANSPORTATION}

The physical transportation of gas occurs through an extensive network of interstate and intrastate pipelines. These pipelines transport gas either to or from each state in the United States, except Hawaii. The predominant flow of gas is from Texas, Louisiana, and Oklahoma to the north central region and the Northeast. Another major artery sends gas from Texas and New Mexico to California. Gas is moved from individual wells to pipelines via gathering lines, which may be owned by either the producer or the pipeline company.

1 The quantity of natural gas is measured in terms of volume, as cubic feet $\left(\mathrm{ft}^{3}\right)$, or in terms of heat content, as British thermal units (Btu). The U.S. Department of Energy (DOE), Energy Information Administration, has adopted the official conversion factor of $1,035 \mathrm{Btu} / \mathrm{ft}^{3}$ of gas (DOE 1991a, p. 300). Consequently, 1 million $\mathrm{ft}^{3}$ of gas equals 1.035 billion Btu of gas. 
Although there are a large number.of producers and pipelines, individual producers may have access to only one pipeline. ${ }^{2}$

\subsection{MARKETING}

Historically, the pipeline company was a "merchant," meaning that the company purchased the gas at the wellhead and then resold this gas at the distribution end. Gas was sold as a bundle of services that reflected both the cost of the gas and a transportation charge. Commencing with the excess supply conditions in 1982 and 1983 - the so-called gas bubble - pipeline companies formed affiliated merchants to sell their excess gas supplies to selected customers at discounted prices. With federal deregulations that encouraged the unbundling of gas sales and transportation, numerous gas marketing firms began to arrange gas sales to any customer that had the contract flexibility to purchase alternative supplies. Today, gas distribution companies buy from and producers sell to a variety of merchants. Gas marketing firms also broker deals between producers and large gas customers.

The story of the gas marketing firm is a reflection of the economic efficiency of the supply side of the natural gas industry. The economic function of the gas marketer is to bring together buyers and sellers, that is, to reduce the transaction costs of doing business. Gas marketers began operating only after numerous buyers and sellers could conduct business because they had access to transportation. Producers were not accustomed to transacting business with buyers in distant locations because historically they simply sold directly to the pipeline company. The gas marketer uses sophisticated financial instruments and diversified portfolios of gas contracts to meet the needs of producers and large customers. The number of marketers increased from essentially none in the early 1980s to about 300 near the end of the 1980s and now has apparently begun to decline. The gas marketer makes an important economic contribution by facilitating transactions, but the marketer competes with his own customers. As the gas market develops and becomes better understood, this function will be performed at reduced costs.

\subsection{DISTRIBUTION}

Gas is transported to the city gate, where it is distributed to customers through LDCs. Such companies are typically investor owned and are locally franchised monopolies, which means that they have been granted the exclusive right to distribute gas within their service territory in exchange for an obligation to serve. LDCs have long been recognized as natural monopolies. The distribution of gas is technically more efficient by means of a single set of mainlines and trunklines than by means of a large number of competitive firms, each with its own set of mainlines and trunklines. The LDC serves residential, commercial, and

2 Major producers may not be disadvantaged. They can leverage the contract terms for the supplies that are captive with their sale of gas supplies when they have choices among alternative pipelines. Smaller producers typically have no such countervailing power. 
industrial customers as well as electric utilities. Some large industrial customers and electric utilities can bypass the LDC and connect directly to a pipeline.

\subsection{MARKET RELATIONSHIPS}

The structure of the gas market has evolved significantly since the early $1980 \mathrm{~s} .^{3}$ The historical market structure is depicted in the top part of Figure 1. Although there are a large number of producers and a large number of pipeline companies, the owner of an individual well had limited choices other than dealing with a single pipeline company. Producers had limited opportunities to sell directly to end users or to LDCs and sold almost exclusively to pipeline companies. Pipeline companies served as dealers or merchants, whereby they purchased the gas, usually under a long-term contract. Historically, the governing relationship in the gas supply business has been a long-term contract (Lemon 1986). At the downstream end of the pipe, the pipeline company sold gas to the LDC, which, in turn, sold to various end users. The LDC would typically purchase gas from a pipeline company through a long-term contract. The significant characteristic of this market structure is that there are few buyers at the front end of the pipeline and few sellers at the distribution end of the pipeline.

The market conditions that influenced the supply of gas over much of U.S. history are characterized by government regulation, long-term contracts, and gas pipeline companies that performed a merchant function and thereby restricted the number of buyers and sellers of gas. These factors are not independent causal variables. The number of market participants and contract terms has been influenced by government regulations - and by deregulation. The conditions characterizing the current market include the elimination of wellhead transmission, open pipeline access, and use of the spot market and the potential to use the futures market for efficient pricing. In the present gas market, large numbers of buyers of gas can conduct business with numerous sellers, and current market prices reflect market conditions.

\subsection{THE DISORDER}

Wellhead price ceilings in the 1970s precluded gas prices from rising to meet demand conditions and instead resulted in a serious shortage of gas in interstate commerce. Gas supply became perceived as limited and unresponsive to prices. The future gas market was expected to be smaller and prices higher because gas was perceived as a "premium" fuel. In other words, gas supply was so scarce that it was going to be rationed just for high-value users. Federal regulations set the supply price of gas at the pipeline company's weighted

3 An excellent description of the evolution of the gas market during the 1980 s is provided by DOE (1989). 


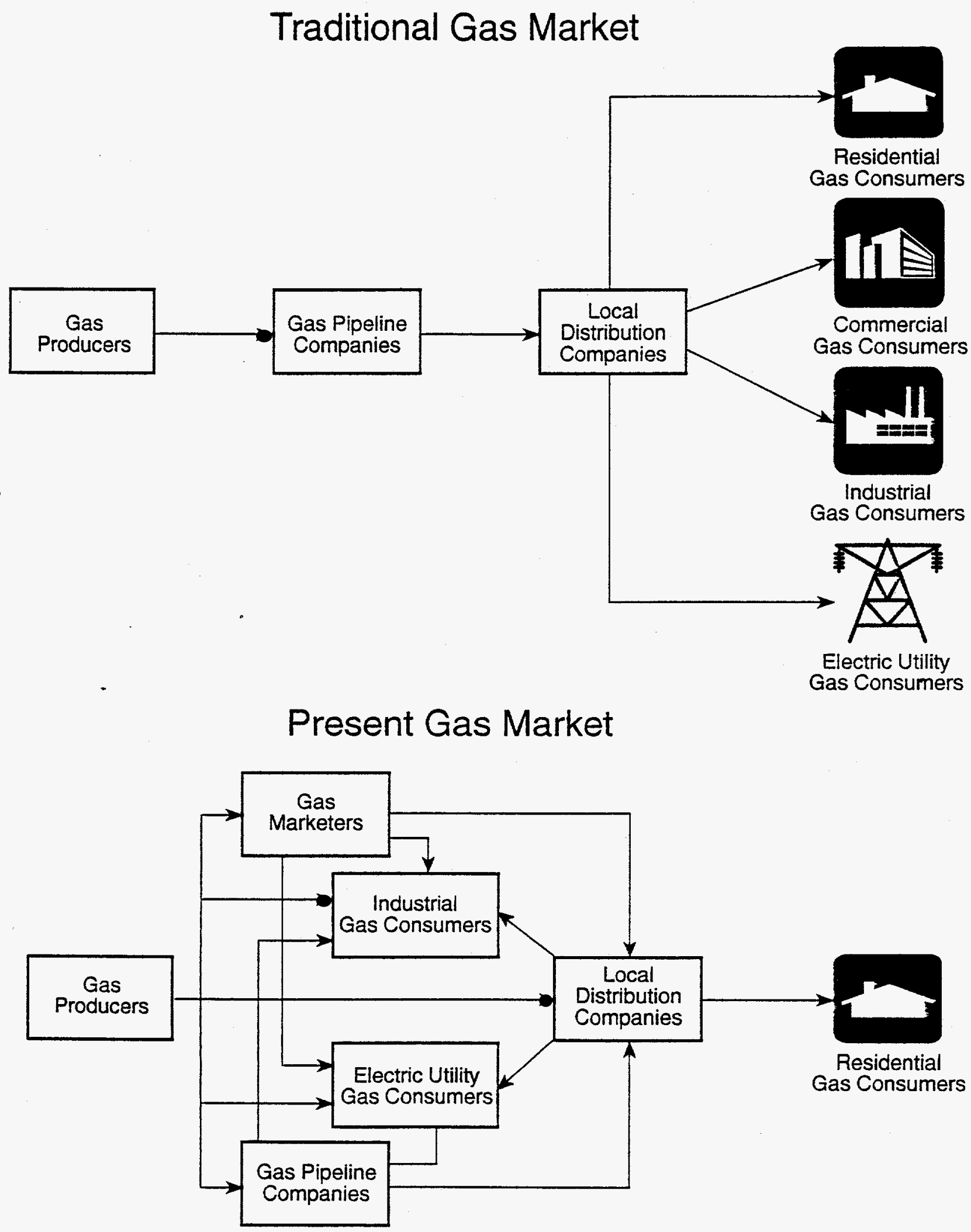

FIGURE 1 Traditional and Present Gas Markets 
average cost of higher-priced new supplies and lower-priced old gas. The price for new supplies after the passage of the Natural Gas Policy Act (NGPA) of 1978 was in the range of $\$ 8$ to $\$ 11$ per million cubic feet (in 1981 dollars), with very high take-or-pay provisions. Fortunately for gas customers, supply proved to be more responsive to prices at far lower costs than were earlier perceived. Unfortunately for pipeline companies, their contracts for gas supply were for the long term, at high rates of required purchases (takes) and with high prices that escalated only upward over time. These contracts became commercially impractical. Starting in 1982, distributors, end users, and consumers had many offers of gas supplied directly from producers or other merchants that were cheaper than the pipeline system's supply. This disorder encouraged gas purchasing practices and contracts to change to shorter terms with market-based prices.

\subsection{FERC ORDERS 436, 500, AND 636}

The Federal Energy Regulatory Commission (FERC) has regulatory authority over interstate utility purchases and sales of gas and electricity. In 1985, FERC issued Order 436, which provided interstate pipelines with the option of becoming contract carriers of natural gas. The objective of Order 436 was to provide competition in the industry by unbundling the transportation of gas from its ownership. Pipeline companies had typically been gas merchants, buying under long-term contract from producers and selling under long-term contract to LDCs and other large users. With Order 436 (and previous Orders 234b and 319), pipeline companies were allowed to provide nondiscriminatory transportation service. The transition from providing bundled sales to being a transporter exposed pipeline companies to costs associated with reformulating prior gas purchases. Order 500 amended Order 436 to provide a means to handle these costs. Once Order 500 was in place, the number of pipeline companies that availed themselves of open access increased. By 1986, 28 major interstate pipeline companies applied to FERC for contract carrier status (Kalt and Shuller 1987 , p. 7). By 1990 , virtually all major pipeline companies in the United States provided transportation access to buyers and sellers. However, by 1992, comparable access to independent merchants offering firm gas supplies at the city gate was still lacking. This deficiency motivated Order 636 , which seeks to improve access by requiring more unbundling of services.

The Interstate Natural Gas Association of America surveys pipelines on a regular basis to determine the amount of gas transported by carriage and the amount transported as sales. "Carriage" refers to gas transported by the pipeline but owned by others, whereas "sales" refers to gas purchased by the pipeline company, transported, and then resold. As seen in Figure 2, in the early 1980s, less than $10 \%$ of the gas was transported as carriage. Almost all of it was transported as sales. Since that time, the share of carriage transportation has increased dramatically. During the first half of 1990 , the level of carriage was $79 \%$. In the first half of 1991 , the level of carriage reached $83 \%$ of interstate pipeline deliveries (Hoffman 1991). The increase in the amount of gas transported as carriage is one of the most significant developments in the gas supply industry in the last decade. 


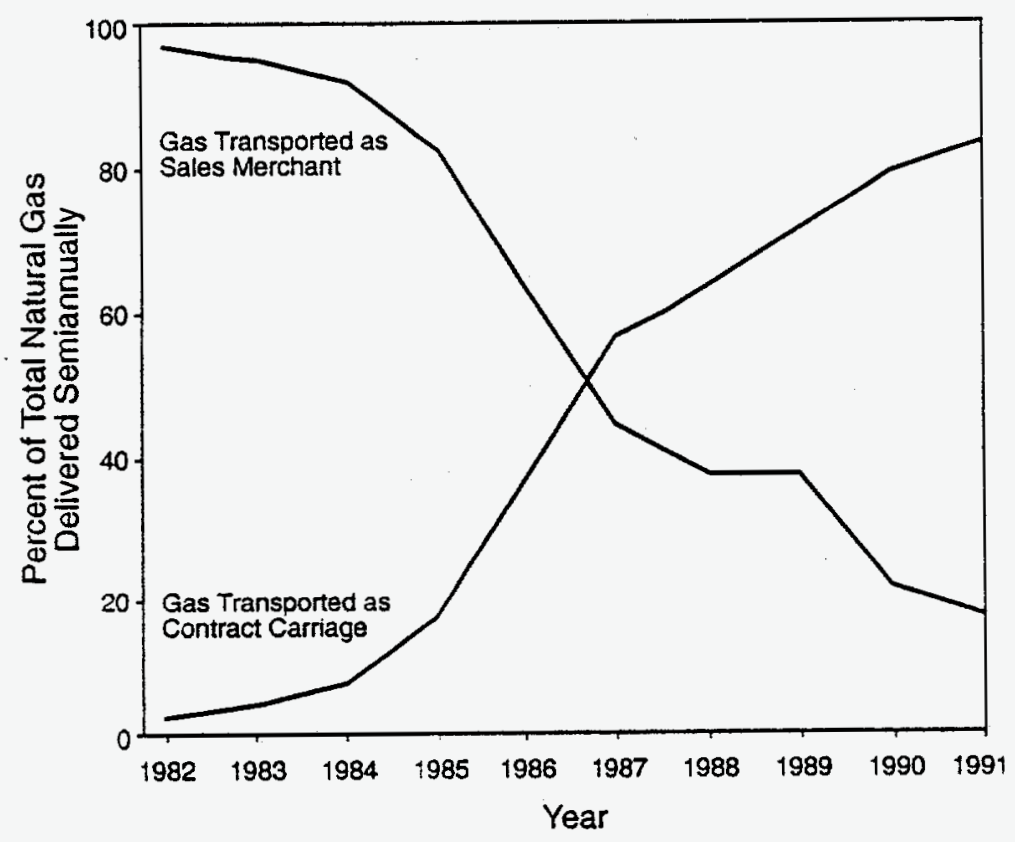

FIGURE 2 Natural Gas Transported as Sales and Carriage for Market (\% of total delivered semiannually)

During the 1980s, the structure of the gas market changed significantly, as depicted in the bottom of Figure 1. Electric utilities, LDCs, and industrial customers are now able to purchase gas from several sources. Utilities can obtain gas from a pipeline company, a pipeline marketing affiliate, an independent marketer, or directly from one of many gas producers. The basic change in the new market structure is that many interstate pipeline companies have become contract carriers instead of exclusively merchants or dealers. As contract carriers, pipeline companies provide transportation for others instead of taking ownership of the gas. The transportation of gas is now separate (unbundled) from its purchase and sale.

The growth of contract carrier transportation enabled buyers and sellers to conduct business with each other. This new business relationship encouraged the development of a spot market in natural gas. During the mid-1980s, many transactions were governed by the fixed prices of long-term contracts signed a few years earlier. Because there was a relatively large supply of gas, termed the "gas bubble," many producers were willing to sell for shortterm delivery at less than the long-term fixed prices contained in contracts. Because of increased access and excess supplies, producers found willing buyers at reduced prices. Brokers and other third-party traders developed business by bringing together buyers and sellers under agreeable terms.

\subsection{THE SPOT MARKET}

The term "spot market" implies that purchases and sales occur on the spot, as in a cash transaction. The spot market consists of a large networks of buyers and sellers of gas 
that operate in different regions. The market does not occur at a single place but is an "over the telephone" (or, more correctly, an "over the fax machine") market. Spot markets are typically loosely organized, without a single market clearing price. The spot market for gas is more sophisticated. Numerous trade publications survey and promptly report prices. Such prices are also posted on electronic bulletin boards as they occur.

The buyers include gas distribution companies, electric utilities, industrial firms, commercial businesses, and trading companies. The sellers of gas include the major and independent gas producers, gas marketers, pipeline companies, and utilities. Spot markets operate at several locations, including distribution locations termed the city gate: New York, Los Angeles, Chicago, and Toronto. Other markets include the Rocky Mountains and east Texas, the Henry Hub, Louisiana, and El Paso, Texas. Gas price movements tend to be highly correlated across these regional markets, but they are, of course, higher near the consumer markets than at the producer end of the pipeline. The regional markets reflect a transportation cost, whereas the Henry Hub price does not. The spot market is a physical market because its function is physically to deliver gas from one owner to another.

The spot market may be more accurately described as a cash forward market, because the physical exchange of gas does not occur on the spot but typically one month in the future. Spot trades are often made in the last week to 10 days of a month, with actual delivery occurring in the following 30 to 90 days (Dearborn 1990). This last week is described as "bid week" and characterized by a frenzy of activity as marketers and other participants put together purchase and transportation deals for the following month (Schlesinger 1990). The literature that describes this process indicates that transactions made with such frequency have small transaction costs.

Trends in the volume of gas traded in the spot market are indicative of major changes in the gas market. As seen in Table 1, before 1983 and 1984, almost no gas was traded in the spot market. During this time, gas was exchanged primarily under long-term (fixed-price) contracts with pipeline companies. The volume of gas traded in the spot market increased dramatically during the mid-1980s, from $14 \%$ in 1984 to about $74 \%$ in 1988 . During the five-year period from 1986 to 1990 , more than half of the gas consumed in the United States was traded in the spot market. Extensive anecdotal evidence indicates that 
the duration of contracts has also shortened considerably since the early 1980s. The purchase and sale of such a large share of gas on a purely monthly spot basis confirm that long-term contracts are not as essential in this business as they were a decade ago. The beginning of another major trend is indicated in Table 1, with the percentage of spot sales decreasing to $50 \%$ in 1990 and falling to $40 \%$ in 1992 and 1993 . Although contracting for gas is returning as a conventional business practice, current contracts tend to be of shorter duration and have market-sensitive price components when compared with contracts of a decade ago.

The price component of current gas contracts appears to be market based. Contract prices are frequently referenced to futures market prices or spot market prices. According to Schlesinger (1991, p. 5), spot gas prices have become the industry standard for indexing long-term gas contracts. Personal discussions with numerous market participants supports the conclusion that the price component of most current contracts is market based, by being referenced to a spot market or to the futures market.

The story that emerges from the data is that the unbundling of gas services (along with wellhead price decontrol) encouraged the development of a market with numerous buyers and sellers. These participants conduct much of their business in a spot market rather than with long-term fixed-price contracts. Open access to pipeline transportation and the spot market (together with gas marketers) brings together the buyers and sellers of gas. The large supplies of gas in the early and mid-1980s encouraged rapid growth in the spot market, as producers attempted to move their excess inventory. The recent decrease in the share of spot purchases is probably in the direction of a long-run equilibrium.

The development of gas spot markets suggests three approaches that PUCs could consider to obtain reliable supplies of gas at current market prices. First, a price cap could be applied at the city gate, but referenced to a spot market. The price could equal the current spot price (or some variation) plus an addition for other costs such as transportation, balancing and storage. Second, LDCs could purchase a share of their gas at the city gate with competitive procurement. LDCs could also purchase a share of their gas and arrange their own transportation and other services. The price at the city gate resulting from competitive purchases could be used as a yardstick to assess the reasonableness of LDC procurement costs. Third, marketers, aggregators, or other third parties could sell directly to ultimate gas customers, which would mitigate the need for any price regulation of gas purchases. 


\section{DURATION OF CONTRACTS}

Both the gas industry and the financial community once believed that long-term contracts were necessary to achieve reliable gas supplies at relatively stable prices and to obtain financing for long-term capital investments. This section reviews the technical literature on contracts to describe the underlying relationship between market conditions and contract duration. The preference of the industry for long-term contracts before the mid-1980s and the rapid shift toward spot and short-term contracts afterward can be explained by this literature. The industry is likely to rely more on contracts than spot purchases, but the contracts will tend to be of shorter duration than observed historically. Such contracts will contribute to the reliability of gas supplies and support the financing of long-term capital investments.

In the first part of this section, a critical distinction is made between the price component of a contract and its duration. The second part of this section considers the marketing of consumer goods and the prevalence of spot transactions. The third part of this section develops the transaction cost model of contract duration. Two other explanations of contract duration, focusing on risk allocation and the principal agent problem, are discussed elsewhere in this report.

\subsection{DEFINITION OF TERMS}

Participants in the gas industry have widely differing views about the terms implicit in a long-term contract. Some participants hold the historical view that long-term contracts are of 10 to 20 years in duration. With shorter-term contracts becoming more prevalent, other participants consider two- or three-year contracts to be long term. Contracts of three to five years are considered long term in several industries, whereas 10- or 20-year contracts are nonexistent. In the gas industry, there is not a widely accepted definition of the duration of a long-term contract. There is, however, a need to define the term as it is being used. A long-term contract is considered here to be three to five years or longer and a short-term contract is one year or so. In a recent interview with a large industrial customer, we were told that he purchases most of the firm's gas under long-term contract and only a small share at spot. By long-term contract, this purchaser meant one year.

The price component of a long-term contract is another source of different views. When the term "long-term contract" is used in the industry, it is frequently not referring to contract duration, but rather implies that the contract has a fixed price. This price component is actually more important than the duration of the contract, even though the contract is described as being long term. Even the term "fixed price" can have different interpretations. A fixed-price contract is sometimes meant to indicate a constant price throughout the duration of the contract. Another interpretation is that the price may be fixed by being tied to an escalator, a price index, or to the futures market. An escalated price may be at a constant rate per year or be linked to a price with random variations. The term "fixed price" is used here to denote prices that are not referenced to the current market; they are 
either constant throughout the duration of the contract or escalate at a constant rate. In contrast, a contract price referenced to the spot market or futures market is referred to as a "market-based price."

A third major component of a gas purchase contract is the take provisions. Contracts typically call for a rate of take less than $100 \%$. When this rate is not achieved by the buyer, contract provisions identify either penalties or other provisions. For example, some recent contracts have take-or-release provisions, by which the seller is free to find another buyer if the buyer does not take at a certain prescribed minimum.

Historically, producer contracts had take-or-pay provisions, by which the buyer paid the producer for the deficiency if the buyer failed to take the minimum. The buyer typically had five years in which it could take the gas for which it had made take-or-pay payments. Take-or-pay provisions provided the seller with income insurance, and hence had value. ${ }^{4}$ In normal market situations, buyers would be expected to pay lower prices for contracts with higher take-or-pay requirements. ${ }^{5}$ The implication of the take provision in gas contracts is that contracts cannot be defined solely by their price and duration terms. Two gas purchase contracts can be of identical duration but have different market-based prices resulting from different take provisions.

\subsection{MARKETS FOR CONSUMER GOODS}

A large body of technical literature on contracts explains the contract duration that is likely to correspond to various market conditions. Contracts serve to minimize transaction costs between buyer and seller. The duration of the contract that characterizes a market is one that minimizes transaction costs. The transaction cost framework is developed to explain the duration of contracts observed historically in natural gas and other products. This framework predicts the duration of contracts that will characterize the gas market in the future as the market responds to regulatory changes. The price component of a contract requires a different explanation.

A commonly held view in the gas supply industry is that long-term contracts are necessary to ensure gas supply reliability. This view can be questioned by noting that one of the largest markets, both in dollar terms and number of transactions, is the market for consumer goods and services. The market includes the basic necessities of life such as food, clothing, shelter, and transportation. It also includes discretionary purchases, such as

4 One way to induce producers to explore and develop more supply during the period of wellhead price controls was to increase the minimum rate of take. The latter term of the contract was not regulated.

5 The problem in the gas industry arose because pipeline companies signed for their highest-priced gas purchases in the 1978-1982 period under long-term contracts with high take-or-pay provisions. Later, spot market purchases that had zero take-or-pay provisions became a source of lower-cost gas supplies. 
entertainment and restaurant dining. Consumers purchase almost all of their goods and services "on the spot." Even basic necessities, for which supply reliability is critical to consumers, are purchased without the use of contracts.

Contracts are not used in most consumer final-goods markets because they are more costly than they are worth. Transaction costs are minimized by consumers making spot market purchases rather than by contracts. Contracts are expensive to write, manage, and enforce, and incentives to breach the contract may occur. The characteristic of consumer markets is a large number of buyers and sellers. Obviously, there are a large number of individual consumers and each consumer has numerous options. If a consumer good is unavailable from one particular seller, the consumer simply goes to another seller. For instance, a consumer purchases gasoline by driving to a gasoline station and making a purchase. Neither the consumer nor the station owner has an incentive to write a contract for such purchases. A customer can minimize the transaction cost of purchasing gasoline by making repetitive "spot" purchases at a single station or by going to alternative gasoline stations. No cost saving would be derived by contracting with a single station. In general, supply reliability is ensured not by contracts but by a market with a large number of sellers. In such markets, contracts would not reduce transaction costs. In almost all consumer markets, contracts do not reduce the costs of transacting business and are therefore not used.

Another commonly held view in the gas industry is that long-term contracts are required to obtain-financing for major capital investments, such as pipelines. Another belief is that electricity generating stations that use natural gas are financed only if long-term contracts for gas are obtained. A casual observation of the consumer goods market can lead one to question this view. Consumer goods, like all goods and services, are supplied with labor, capital, and raw materials. The supply of retail goods requires, as a minimum, a capital investment in a retail outlet. For example, the distribution of automobiles requires a capital investment in a dealership plus a multimillion-dollar investment in manufacturing facilities. Supplying gasoline also requires an investment - in service stations - plus large capital investments in petroleum refineries. Capital investments made to supply consumer goods are not financed through long-term contracts because consumers do not purchase such goods through contracts. In these markets, there appears to be no connection between capital investments and long-term contracts.

Contracts are not used extensively in the market for consumer goods, even when consumers engage in repetitive purchases from the same supplier. In the gas industry, longterm contracts are frequently thought to be necessary because they imply price stability. This price stability is generally argued to be of major benefit to gas customers. Observations of the market for consumer goods suggest that consumers accept such price risks; at the least, they are unwilling to forego income to achieve price stability for particular goods.

Another observation of the consumer goods market also suggests that an adequate level of price stability is maintained without the use of contracts. Consumer goods, including the basic necessities of life, are purchased primarily in a spot market, where prices are volatile. Although prices can be random from one period to the next, consumers are not 
motivated to take measures against such uncertainty. Indeed, most consumer goods experience some price risk over time, but such risk is relatively unimportant. If a particular expense were to represent a large share of the consumer's income, volatile prices might be considered a more serious problem. For instance, the rent or mortgage payment represents a large share of a consumer's current income, and most consumers prefer this cost to be stable from month to month. The existence of fixed-price mortgages is explained by the fact that consumers are averse to large fluctuations in their major expenses and by the fact that creditors are better able to bear these risks.

These observations of the consumer goods market have several implications. First, contracts are seldom used in consumer markets because they do not reduce the transaction cost of purchasing. Second, the supply of goods, including the necessities of life, is highly reliable without the use of contracts. Third, large capital investments are made to supply consumer goods, and the financing of these investments is not backed by contracts. Consumer goods are not unique in the sense of obeying different economic laws from intermediate goods. The fundamental characteristic of the market for consumer goods is a large number of buyers and sellers of relatively homogeneous goods. This characteristic reduces the need for contracts. In other markets having these same characteristics, longterm contracts are not likely to be prevalent.

\subsection{CONTRACT DURATION}

A large body of technical literature has been written to explain the duration of contracts in various markets. The concepts discussed in this literature explain and predict the duration of contracts observed under different market conditions. This literature also defines the contract duration that facilitates transactions in the gas business. This section provides an economics-based explanation of the duration of natural gas contracts prevalent in the industry before the mid-1980s and of the change to shorter-term spot purchases. The duration of gas contracts likely to appear in the future is suggested.

The conceptual explanation of contract duration developed here has its genesis in the work of Coase (1937) on transaction costs, for which he was awarded the Nobel prize. The transaction costs model as applied to contracts was developed by Williamson (1979, 1983, 1985). ${ }^{6}$ The analysis has been extended and applied by many others, but the work of Joskow $(1987,1988)$ on the duration of coal contracts with electric utilities is particularly noteworthy.

The view that emerges in this literature is that the underlying motivation to use contracts is to minimize the transaction costs of purchasing and selling goods and services. Buyers and sellers determine the contract duration with the overall objective of minimizing

6 Recent literature on management puts a different emphasis on Williamson's work. Human capital develops from business relationships. Neither party gains in breaking or damaging a contract, because it erodes the human capital that has been established. Thus, contracts typically are more self-enforcing and less subject to opportunistic behavior than would be thought. 
transaction costs. The numerous components of transaction costs include negotiating, monitoring, enforcing, and renegotiating contract extensions. Additional costs include various risks such as opportunistic behavior and breach of contract. The costs of a contract that is too short in duration result from renegotiation costs and particularly from the incentive each party has to hold the other hostage by demanding more favorable terms. The suggested model is that buyers and sellers engaged in contracting consider all these costs and attempt to minimize them by writing a mutually beneficial contract of appropriate duration.

One cost of a contract that is too long in duration is the cost of attempting to anticipate future uncertainties. Over the long term, actual market conditions will deviate from those initially anticipated in the contract, and the difficulty of forecasting all possible outcomes increases. ${ }^{7}$ Long-term contracts become more complex and costly to write. A longterm contract is likely to result in one of the parties being dissatisfied with the terms of the agreement. This party may be inclined to breach the contract. Enforcement costs can be high, particularly if they involve litigation.

Another cost of a long-term contract is the possibility of opportunistic behavior, in which one party takes undue advantage of the other as circumstances warrant. For instance, suppose that an LDC signs a long-term fixed-price contract in an effort to obtain reliable gas supplies. In an extremely cold winter, spot prices rise significantly and the physical delivery of gas becomes limited. A supplier that is technically able to perform under contract may behave opportunistically by declaring a good faith effort but not making delivery at the fixed price. Instead, the available supplies may be sold on the spot market. In this case, opportunistic behavior results from the low (and fixed) contract price relative to the spot price and not from contract duration per se. The consequence is that supplies are less reliable than they would be if spot market purchases were being made. Various types of opportunistic behavior increase the risks and therefore the transaction costs of long-term contracts.

Opportunistic behavior is more likely to arise with long-term contracts than with short-term contracts because unforeseen events that facilitate such behavior are more likely to arise in the distant future. Such behavior is more likely to be feasible if one party has large sunk costs and a high degree of "asset specificity," which means few alternatives. Examples include gas wells, pipelines, distribution systems, and gas-using generating stations, which are, of course, the major investments in the gas supply system. The rate of return on each of these assets requires performance by other parties in the system. A generating station is economically feasible only if the pipeline is reliable over the long term. A gas well is profitable only if a long-term relationship is maintained with the pipeline company. The conditions that give rise to the use of long-term contracts and enable them to reduce transaction costs more than shorter-term contracts also bring with them additional risks and costs. Long-term contracts are costly and risky, but they may have lower

7 Although individuals are intentionally rational, they actually behave with "bounded rationality" that limits their ability to write contracts that will cover all possible contingencies. Associated with a long-term contract is an increased probability of eventual dissatisfaction and a decreased probability of anticipating this dissatisfaction. 
transaction costs than short-term contracts if there is a high degree of asset specificity and assets are long-lived.

Joskow's (1987) analysis of coal contracts concludes that the duration of a contract depends on the extent the investment is "relationship specific. ${ }^{18}$ An extreme example is a single coal mine that produces coal for a single electricity generating station that is located near the mine. The investments in developing the coal mine and constructing the generating plants are relationship-specific, because the financial feasibility of the investment requires a long-term business relationship. The economic value of the coal mine depends on its ability to sell coal to the utility. Similarly, the value of the generating station requires that it have access to reliable coal. In this case, the utility will purchase coal by means of a long-term contract, in which the duration of the contract may coincide with the economic lifetime of the investments. The long-term nature of the investments (the mine and the generating plant) and the usefulness of long-term business relationships suggest that there be a contract of commensurate duration. Because the terms of purchases are defined in a long-term contract, repeated purchases of coal are made with relatively low transaction costs.

In this example, if contracts were short term and successively renegotiated, transaction costs would increase. One cost of renegotiating short-term contracts is that each party could attempt to hold the other hostage because of the relationship-specific characteristic of the investment. Assuming that the utility and the coal mine are each earning a reasonable rate of return, this return on investment becomes a target in the renegotiation. Each party has an incentive to revise the contract in its favor. The costs of renegotiating short-term contracts can be avoided by using longer-term contracts. When assets are relationship-specific and long-lived, a long-term contract may have transaction costs that are lower than those of a shorter-term contract.

The notion of a relationship-specific investment is developed by Williamson (1983), who notes three conditions under which an investment by one firm may be for the nearexclusive use by another firm. The first condition is "site specificity," which means that the investment is made at a place that is geographically convenient for the second firm and the asset is immobile. The second is "physical asset specificity," which means that the asset is designed and constructed for transactions with a particular customer. The third is "dedicated assets," which are investments that would not have been made in the absence of opportunity to sell to a particular customer. When there is a high degree of asset specificity, a long-term business relationship can efficiently be conducted through a long-term contract.

8 Industrial firms often use spot contracts for coal, which helps identify asset specificity. Industrial firms make use of technology that can use various types of coal, as defined by their ash, heat (energy), and sulfur content. Neither the mine nor the industrial firm can be subject to opportunistic behavior because there are many other buyers and sellers. Electric utilities tend to design their plants for specific coal types. They become dependent on just the one mine that produces the coal type for which their generating facility has been designed; similarly, the mine becomes dependent on the utility for the premium that the utility is willing to pay above the price of generic coal. Differences in asset specificity between the utility and the industrial firm explain the considerable differences in contracting practices. 
The above three conditions of asset specificity apply to each segment in the gas industry. Consider, for instance, gas producers, pipelines, and gas-fueled electricity generating stations. The assets are site specific and physically specific, and each is dedicated for use by the other two. A gas well is highly immobile and may have its gas gathered and transported by a single pipeline. A well could be developed to produce gas for one particular pipeline, if only one line were accessible. Gas-fueled generating stations are also highly immobile and may be constrained to purchase gas from a single pipeline. Gas pipelines are also geographically and physically specialized because their economic value derives from transporting gas from one specific point to another. The station and a gas well could each be considered "dedicated assets" if the initial investments were made only because of the existence of a single pipeline. The implication of asset specificity is that a long-term contract may have lower transaction costs than a short-term contract that is frequently renegotiated.

The two extremes in contract duration involve not using contracts. In one case, any contracting would increase transaction costs and business is simply conducted in a spot market. As discussed above, most consumer goods markets operate this way. In the second case, a long-term business relationship can be conducted most efficiently by one firm acquiring ownership of another firm. Certainly, one incentive for vertical integration is to minimize transaction costs (Blair and Kaserman 1983).

The transaction cost interpretation of contract duration provides a compelling explanation of the long-term contracts observed in the gas industry until the last few years. Figure 3 illustrates the probable relationship between transaction costs per gas contract and the duration of contracts. In the traditional gas market (the early 1980s), transaction costs

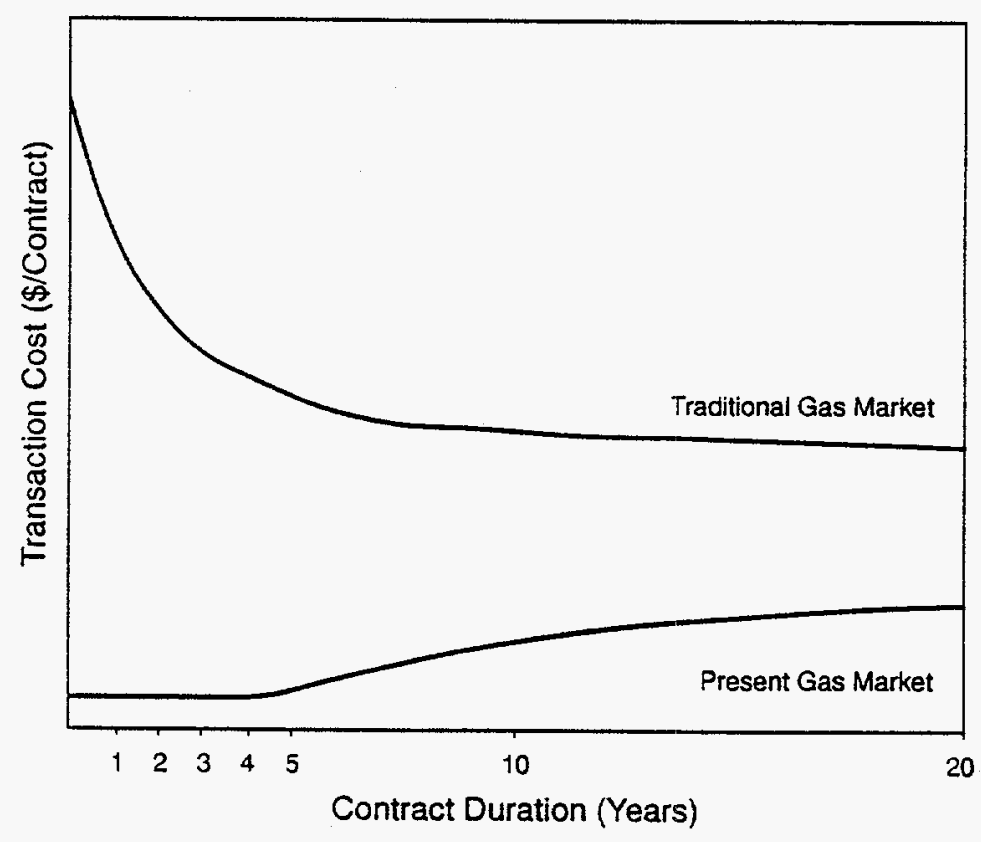

FIGURE 3 Relationship between Transaction Costs and Contract Durations 
were lower for long-term contracts of 10 and 20 years than they were for short-term contracts. Producers needed long-term contracts with pipeline companies because producers had specialized assets and no alternative but to contract with a single pipeline company. The transaction costs of shorter-term contracts would have been higher because of renegotiation costs, including the risks of opportunistic behavior. LDCs, electric utilities, and other large buyers had large capital investments that required a reliable supply of gas, and the only source of supply was a single (or at most a few) pipeline(s). The pipeline company also required contracts to obtain initial financing, and it continued to conduct business on this basis. Long-term contracts facilitated the conduct of business at low transaction costs. However, there were no feasible alternatives. One possibility would have been vertical integration, in which large users would have acquired ownership in pipelines and producing companies. However, the Public Utility Holding Company Act (PUHCA) restricted such ownership by electric and gas utilities.

The economic usefulness of long-term contracts began to change drastically in the mid-1980s. Open access transportation, resulting from FERC Order 436, permitted numerous producers and marketers to sell gas to many large customers and to purchase transportation separately. Yet this ability applied largely to spot transactions, because access to highquality firm transportation was not required by FERC in implementing an individual pipeline company's open access programs. On April 6, 1992, FERC issued Order 636, which severs the pipeline company's sales service from its transportation service and requires all firm sales by various merchants to have access to firm transportation on the same terms. Through these orders, FERC is replacing markets in which a single buyer contracts with a single seller with markets in which a large number of buyers can conduct business with a large number of sellers on either a spot or long-term basis. In such markets, long-term contracts do not have transaction cost advantages over short-term contracts or even over spot purchases.

Asset specificity should not be viewed as a physical characteristic of the asset but as a function of the number of alternatives in a market. Suppose the above coal mine example were changed so that several comparable mines had open access to several coal-burning generating stations. No single coal mine would now be dedicated for use by any particular generating plant. A long-term business relationship between a particular buyer and seller would no longer be necessary. A large number of buyers could do business with a large number of sellers. There would be no need for long-term contracts, because such contracts do not reduce transaction costs of short-term or spot purchases. In this revised illustration, the coal mine and generating plant would remain large-scale investments requiring a payoff and a reliable market over the long term. However, in this market, reliability would be maintained and transaction costs minimized by short-term contracts or even by spot purchases.

Gas wells, pipelines, distribution systems, and gas-fueled generating stations are large-scale investments that had a high degree of asset specificity. In terms of new market opportunities, asset specificity has now largely disappeared. When pipeline companies became contract carriers, many buyers obtained access to many producers. The specific assets, such as gas wells and generating stations, no longer must be used with any specific 
asset. The characteristic of a market with numerous buyers and sellers is that no participant needs to transact business with any other specific participant with a long-term contract. As depicted in Figure 3, the transaction costs of purchasing gas are much lower in the present gas market than in the traditional gas market because of the feasibility of spot purchases, with their relatively low costs. In the present and evolving market, long-term contracts will most likely be referenced to spot or futures markets and therefore will not have the risks and costs associated with the fixed-price contracts of the traditional market.

When pipeline companies were dealers or merchants in gas, the assets in the industry were relationship-specific. When the pipeline companies became contract carriers, asset specificity for the purchase and sale of gas disappeared and, with it, much of the value of long-term contracts. Pipeline companies lost most of their asset specificity when their services were unbundled and transportation was separated from purchase and sale. Buyers and sellers of gas no longer have highly specific assets that require long-term commitments to ensure a reliable market. Instead, reliability is ensured by the market in the form of a large number of business options. The market for the purchase and sale of gas can now be conducted efficiently without the use of long-term contracts.

The transaction cost model of contract duration developed by Williamson, Joskow, and others provides an explanation of the long-term contracts observed in the gas industry before the early $1980 \mathrm{~s}$. The model also accounts for the use of spot transactions and shortterm contracts currently in use in the gas industry. When there is open access,. long-term contracts at fixed prices will not return as the standard for purchasing gas. Future gas supply portfolios will contain a mixture of spot and short-term purchases and perhaps some long-term purchases, but they will not be dominated by long-term and fixed-price contracts.

A recent study by Palmer et al. (1993) on contracting incentives in electricity generating fuel markets also looked at contract terms in two other industries: petrochemicals and newspaper publishing. These industries use energy-intensive inputs (natural gas in the petrochemicals industry and newsprint in the newspaper publishing business). Each industry is characterized by large capital investments and requires inputs to be supplied with a high degree of reliability. The industries are also characterized by relatively few buyers doing business with relatively few sellers. Although much of the evidence is anecdotal, Palmer concludes that contracts for inputs are typically for one to five years. Some shorter-term contracts and spot purchases were observed, as were a few longer-term contracts and vertical integration. Palmer also concludes that the transaction cost framework provides an adequate description of contract duration in these two industries. Given the size of the capital investments in these industries and the degree of asset specificity, contracts from one to five years in duration appear to minimize transaction costs. Palmer observes that the price component of the contract in each industry is neither totally rigid nor a spot price but follows market prices with periodic adjustments. 
Market conditions in the gas supply industry are close enough to those in the petrochemicals and newspaper publishing businesses to suggest some generalizations:

- Palmer concludes that the transaction cost model accounts for the preferred duration of contracts in these industries. The implication is that in those regional gas markets with a limited number of participants, contracts from one to five years in duration may come to be preferred. In cases where the spot market is highly robust, gas supply portfolios contain more spot purchases; in cases where this market is "thin" (with poor access or a limited number of buyers and sellers), contracts of one to five years are preferable.

- The absence of long-term contracts in these two industries suggests that the former preference for 10- or 20-year contracts by utilities cannot be explained simply by the transaction costs of contract duration. ${ }^{9}$ Contracts of such long duration are apparently not required to maintain reliable supplies or obtain financing for capital investments, at least as suggested by these two industries.

- The newsprint and petrochemicals industries make periodic adjustments to market-based prices. These two industries do not have access to competitive market prices as revealed in a futures market. With the development of a gas futures market and numerous regional spot markets, gas contracts would be likely to have more flexible, marketbased prices than observed by Palmer in the industries she studied.

These generalizations apply to the industrial and utility sector and seem reasonably sound despite being based on anecdotal empirical evidence. As part of the collaborative effort with the State of Maryland, we interviewed gas marketers and one large industrial customer. The view to emerge from these discussions is that market participants have little interest in longterm fixed-price contracts. Contracts of almost any duration are referenced to the spot or futures market.

9 Historically, both the price and take rate components of gas contracts and their lengths were influenced by regulations on gas from the wellhead to the burner tip. The Federal Power Commission (predecessor agency to FERC) initially encouraged pipelines to have dedicated reserves under contract to equal 20 times their annual sales. Prices were set by regulation instead of market forces, a situation that also encouraged contracting at fixed prices. 


\section{THE FUTURES MARKET}

The previous section focuses on the duration of contracts and explains the trend toward shorter-term contracts and spot purchases in terms of minimizing transaction costs. This section begins to consider the price component of natural gas contracts by discussing the futures market. ${ }^{10}$ The literature indicates that when a futures market exists for a particular commodity, the physical exchange of that commodity is likely to occur at prices referenced to the futures market. This section concludes that the development of the gas futures market facilitates the purchase and sale of gas at market-based prices. It describes the gas futures market and discusses the link between futures prices and physicals (actual commodity) prices.

\subsection{GAS FUTURES}

In April 1990, a futures market in natural gas was opened by the New York Mercantile Exchange (NYMEX). Trading in futures contracts occurs on the trading floor of the NYMEX with an open-outcry auction type of market. Financial performance of contracts is guaranteed by NYMEX, but physical delivery of products is not guaranteed (Dearborn 1990). Futures markets in agricultural products have a long, successful history and have recently been expanded to include currencies, stock market indexes, and energy. A futures market for heating oil began in 1978. Oil contracts have been traded on the NYMEX since 1983. Futures contracts for propane and unleaded gasoline are also exchanged on the NYMEX.

A futures contract is a contract to purchase or sell a standardized product of exact specifications ${ }^{11}$ at a particular time and place and for a specified price. A futures market is a market for contracts, as opposed to the spot market, which is a physicals market. The objective of a spot transaction is to exchange a physical good. The objective of a futures contract is to take a price position on the commodity. The participant in the futures market purchases a contract to exchange a commodity at some future time at a specified amount and price. A futures contract to deliver a product in the future is typically fulfilled by exchanging the contract with one that promises to take delivery of that commodity on the same date. The completed transaction is one of settling price differences. The futures market is basically a market for prices and not a market in which goods are actually exchanged. In general, in actively traded commodities, about $1 \%$ or $2 \%$ of the contracts are settled by delivery. About $1 \%$ of natural gas futures contracts are settled by physical delivery at Henry Hub.

Futures markets perform several economic functions. As noted in futures market textbooks such as one by Kolb (1991), the most important function of this market is that it

${ }^{10}$ An excellent description and analysis of the gas futures market is provided in Dearborn (1990). The significance of the gas futures market is discussed in Clark and Clark (1984).

11 The complete specifications of a gas futures contract are defined in Ellis (1991). 
discovers and conveys market-based prices. The second function of this market is that it facilitates efficient hedging against price risks. Futures markets also provide an opportunity for speculators. With their frequent buy and sell orders, speculators are always available to participate in futures transactions. In this way, they contribute to the functioning of the market.

A futures contract for gas is a contract for 10,000 Btu of gas, plus or minus $2 \%$. Actual transactions occur in multiples of this basic contract. Prices are quoted in dollars and cents, such as $\$ 1.75$ per million Btu. Futures contracts vary in duration from a few months to a maximum of 18 months. The contracts are exchanged on a daily basis on the NYMEX, with trading terminated eight business days prior to the month when delivery begins.

The point of delivery in this market is Henry Hub in Louisiana. Henry Hub is a major gas interchange, relatively close to major producing areas and some consuming areas. Transportation to and from the Henry Hub is offered by seven major interstate pipelines and two intrastate pipelines. A well-developed spot market for gas also exists at Henry Hub. The significance of this delivery point is that it is a major market at which gas is traded (termed a physicals market) and that it thereby links futures market prices with physical exchanges. The market price of gas at other locations can be referenced to the Henry Hub price by having it reflect transportation costs. Henry Hub can be considered the central marketplace for the purchase and sale of gas.

\subsection{PRICE DISCOVERY}

Futures markets discover and convey efficient prices for the physical product; they do not determine these prices. This point is enormously important but frequently misunderstood. Actual market prices are determined by the underlying supply and demand conditions in the market. Gas producers making production decisions and gas customers making utilization decisions determine the market value of gas. The futures market reflects these market forces in terms of competitive prices. These prices, in turn, are the market signals on which buyers and sellers base their business decisions. One implication is that gas contracts can now be written to reflect competitive market prices as revealed in the futures market. ${ }^{12}$

Futures prices are widely disseminated and readily available. Futures prices can be read from a screen in real time at locations throughout the country. Those with less urgent

12 In the post-NGPA period, there has been an evolution in the price indexes used to link the wellhead price of natural gas to market-based prices in long-term contracts. The intent was always to find the competitive price. Initially, these contracts tied natural gas to alternative fuels. These contracts proved unappealing when oil and gas price trends diverged in the mid-1980s and gas-togas competition developed. Contract indexes were next tied to a basket of prices for pipeline system supplies and then to a basket of spot-market prices as reported in various trade publications. Finally, with the advent of the futures market, the prices in contracts of one year or so are becoming indexed to the futures market price. 
needs can obtain futures prices from major daily newspapers such as the Wall Street Journal and the Washington Post. Newspapers print various daily prices, including the settlement price at the end of the day for contracts that have matured during each of the subsequent 18 months. The availability and use of futures market prices does not require participating in or even understanding the market.

In basic economics textbooks, the conditions of a competitive market are listed as a large number of buyers and sellers, a homogeneous product, easy entrance and exit, and perfect information. When these conditions characterize a market, a product is produced at minimum cost and priced competitively, and resources are used efficiently. There are a large number of buyers and sellers of futures contracts, and almost anyone - with sufficient funds - can enter the market. Futures markets are monitored and regulated so that no single participant can "corner the market" by purchasing or selling large enough quantities to affect price. Natural gas measured in Btu content and delivered at Henry Hub is a homogeneous product. Futures market prices tend to accurately reflect all available information. In this sense, the prices are efficient. As new information about the supply or demand for a product becomes available and is assessed, participants purchase or sell futures contracts accordingly, and prices change.

A large body of scientific investigation concludes financial markets are economically efficient. These markets include money markets that trade short-term financial instruments and the capital market, in which long-term financial claims are traded. In efficient markets, current prices accurately reflect all available information but can include some random variation. Futures markets, including the market for natural gas, are also reasonably efficient. The gas futures market has been in operation less than four years and is not assumed to have been perfected. In this study, the market is considered adequately competitive to reveal market prices that are close to efficient prices and closer than any alternative available price.

The significance of this price-discovery property of futures markets is that contract prices for the physical exchange of goods can be referenced to the futures market. Historically, one of the major inefficiencies in the gas market was the absence of current market prices. Gas prices were regulated from the wellhead to the burner tip. These prices did not accurately reflect supply and demand conditions, nor did they result in an efficient use of gas resources. Consumers observed and responded to an average of the long-term regulated prices rather than a competitive marginal price. ${ }^{13}$ In contrast, futures market prices are determined in a competitive market and are therefore reasonably efficient.

${ }^{13}$ Even if these long-term fixed-priced contracts had been negotiated freely and not been subject to price ceilings, a large portion of these types of contracts would have contributed to large boom-bust cycles in exploration and use whenever parties adjusted to changing market conditions. The marginal price would be subject to periodic, very substantial price swings. 


\subsection{HEDGING AND SPECULATING}

An important function of futures markets is to provide an efficient mechanism to transfer risk. By a process known as "hedging," producers, merchants, and consumers of a commodity can reduce their exposure to the risk of fluctuating prices by buying or selling futures contracts. Using the futures market to hedge against price risks requires participation in the market in the form of purchasing and selling futures contracts.

The futures market can be used as a low-cost mechanism to provide insurance against adverse price changes. Suppose that a gas producer contracts to sell gas to an industrial customer for the next few years at the (volume-weighted average) spot market price at Henry Hub, where transportation is arranged separately. The producer is exposed to a risk of a price decrease and may be averse to such risk. The industrial customer may be concerned about a future price rise and particularly about a price shock. The participants in this transaction can each use the futures market to insure against unfavorable price movements. The producer obtains insurance against a price decline by a futures contract to sell gas in one year at the one-year futures price. If gas prices decrease by the end of the year, the futures contract earns a profit, which is the difference between the current market price and the higher contract price. However, the producer receives less revenue than anticipated from the physical sale to the industrial customer. The actual protection provided by the futures contract depends on the share of the transaction that the producer decided to hedge. If the market price of gas were to rise throughout the year, the producer would be rewarded on gas sales but would incur a loss on the futures contract. Regardless of the future price movement, the producer could successfully reduce risk through a futures contract.

A futures hedge is a contract purchased with the intention to insure the participant against an adverse price change. As of early 1991, speculators held only about $4 \%$ of the long and short positions in gas futures. Marketers held about $92 \%$ of the (long) contracts to purchase gas and also about $44 \%$ of the short positions (Mitchell 1991). Gas producers held about $44 \%$ of the short positions and less than $1 \%$ of the long positions. Participants in the gas futures market are clearly in the business of buying and selling gas. These participants are not primarily price speculators but are using the futures market to offset a price risk inherent in their purchase or sale. Gas marketing firms, such as Enron Gas Marketing, make extensive use of the futures market to offer gas contracts of various duration that reduce spot and futures price risk.

A futures market cannot function unless it attracts speculators who are willing to take on the risk that producers, merchants, and consumers want to shed. By increasing the volume of bids and offers, speculators facilitate hedging on competitive terms. Speculators can be viewed as specialists in taking risk. Society, as a whole, benefits from their participation in the futures market because risk is transferred to those who are willing to carry it at lowest cost. Speculators contribute to the functioning of the market because of their large number of transactions. Although speculators hold a small share of total market positions, the frequency with which they purchase provides liquidity to the market, which is 
critical to its functioning. When a producer or marketer wishes to purchase or sell futures contracts, there is always an obliging speculator willing to provide that liquidity at a market price. $^{14}$

\subsection{FUTURES AND PHYSICALS}

The significance of the futures market for this study is its interdependence with the market for physical goods (i.e., physicals). The supply and demand for gas determine its price and the amount that is produced and consumed. The futures market reflects the underlying causal variables in the form of futures prices. The use of these prices in gas contracts facilitates exchange by sending correct market signals to producers and consumers.

To restate the distinctions between gas physicals and futures markets, the futures market operates at a single place - NYMEX in New York City - although transaction orders can be placed from almost anywhere in the country. The futures market is merely a paper market, in which standardized contracts are traded and prices are discovered and conveyed. In contrast, a physicals market effectuates the physical exchange of a good or service. The gas physicals market includes the purchase, sale, and delivery of gas. The gas physicals market is nationwide in that producers and consumers are located throughout the United States. ${ }^{15}$

One connection between the futures market price and the price of the good in the physicals market is the convergence of these prices when the futures contract matures. The futures price of gas for delivery the following month tends to converge to the spot price of gas to be delivered the following month at Henry Hub. A futures contract is a contract to physically deliver 10,000 Btu of gas at Henry Hub at a specified time and price. The contract could be honored by delivering and accepting delivery of the gas at the initial price in the futures contract. The contract price at delivery must be nearly equal to the physicals market price at the same time and place. If the contract price were lower, buyers of physicals would buy the contract and take delivery. If the contract price were more than the physicals market price, the buyers would purchase physicals, causing the price of physicals to rise and the futures contract price to fall. In this market, futures contract and physical prices should converge.

The gas futures market is new, and prices do not yet converge as closely as they do in other futures markets. Part of the explanation may be a measurement problem, because spot and futures prices vary in real time and must be measured at exactly the same point in

14 The speculator takes a futures position at what is expected to be a disequilibrium price and makes a profit as the prices reach a new equilibrium price. For instance, if a speculator believes that a particular contract is undervalued by the market, the speculator will purchase the contract and thereby tend to increase its price. In this way, speculators contribute to the stability of the market.

${ }^{15}$ In 1990, the United States imported about $7 \%$ of the gas it consumed (mostly from Canada) and exported about $4 \%$ of its supplies. 
time. For instance, the futures price at the end of any given day would not correspond to a sales-weighted-average spot price for that same day. Measurement issues aside, the futures market price for one-month delivery is a reasonably close approximation to a competitive market price for gas.

Several theories of the futures market prices have been developed, and these theories relate futures prices to physicals markets. As developed by Hull (1989), the forward or future physical price of a particular good will closely match its futures market price. The forward price of a good tends to equal its spot price, with an adjustment for physical storage and an interest charge. Certainly one way to deliver a good in the future is to buy it now and store it. Arbitrage ensures that the future price of a good cannot exceed or be less than the cost of purchasing the good on the spot market and storing it until the delivery date. Similarly, the futures price of a good will tend to reflect its forward price and its current spot price adjusted for interest and storage costs. Hull (1989, p. 43) refers to empirical studies of foreign currencies and U.S. Treasury bills that conclude that forward and futures prices are extremely close. An alternative theory of futures prices asserts that they equal future expected physicals prices. The theme of these various theories is that futures prices are based on market assessments of the actual good.

The literature on the futures market indicates that, in almost all cases in which a futures market exists, the actual exchange of the physical commodity tends to occur at prices related to futures prices. The key relationship between the actual cash price of a good and its futures price is cash price $=$ futures price + basis. Cash price refers to the current cash price for the physical good. Futures price refers to any future time for which the futures price exists. Basis includes the "spread" between the futures price of a good and its current cash price, and it includes transportation from Henry Hub to any destination. For instance, in the summer months, the cash price of gas tends to be lower than futures winter prices, causing the basis to be negative. The basis is higher in locations that are far from Henry Hub than in locations at the Hub or in neighboring locations. Changes in transportation rates, in seasonal loads, and in pipeline capacity constraints are reflected by changes in the basis.

Numerous mechanisms currently exist to enable a gas purchaser to contract for gas at the NYMEX futures price plus a basis charge. One mechanism, termed an exchange of futures for physicals (EFP), enables the holder of a futures contract (long or short) to exchange it for physical delivery. For instance, it enables the holder of a futures contract to take delivery of gas or accept delivery at some location other than Henry Hub. The holder of this contract could approach the NYMEX trading desk, hoping to find the holder of the contract to deliver the gas during the same month. Because the NYMEX trading desk is connected to a large network of buyers and sellers, a willing seller of physicals might be found. The remaining task would be to negotiate the basis, which is simply the cost of transporting the gas to the agreed-upon delivery point. An EFP can also exist between the holder of a futures contract and the purchaser or seller of gas physicals who is not participating in the futures market. The significant characteristics of the transactions are 
the link between futures contracts and physical delivery at locations throughout the United States.

A transaction simpler than an EFP that translates futures prices into physicals transactions is termed the "passive hedge." Industry participants can use futures-priced buyand-sell sheets that list prices at various locations for future delivery, in which the prices equal NYMEX futures prices plus an adjustment for basis risk. These price lists are sent frequently to buyers and sellers via a fax machine.

\subsection{REFERENCING FUTURES PRICES}

A frequent justification for government regulation is the failure of private markets to produce efficient prices and thereby send efficient signals to producers and consumers. The task of regulation is to encourage market conditions that mimic competitive markets. The typical characteristics of a noncompetitive market are inefficient prices and undersupply. The discovery of efficient prices by futures markets provides a significant contribution to the regulatory process. Allowable gas costs could be determined by market prices as referenced by the futures market.

The recommendation that futures market prices be used in gas contracts has received extensive support, even before this futures market developed. Clark and Clark (1984) recommend the use of these prices as competitive market prices. Lemon (1986, p. 113) states that gas prices could be tied to a futures market price. As noted by Dearborn (1990, p. 5), futures market prices have tended to be reference prices in virtually all markets that have futures markets, and he expects this to be true in the natural gas market as well. The use of futures market prices as reference prices for physicals is an important lesson for the gas industry.

Futures prices are becoming increasingly important in pricing oil contracts. Roeber (1990) argues that futures market prices will be used more extensively for pricing of physicals in the oil industry, because the evolution in this industry is following that of several other industries. Roeber notes that copper pricing evolved from producer pricing to spot-market pricing and then to complex forms of pricing against futures. The gas market has evolved from one that used long-term fixed-price contracts to one using spot-market pricing and prices referenced to the futures market. Lucas (1991) notes that crude oil contracts were traded on the NYMEX for about four years before the market became widely used as the reference price for crude. Lucas (1991, p. 23) also predicts, "NYMEX could be the dominant, if not sole, reference for gas prices by 1995." The National Petroleum Council (NPC 1989) notes that the oil futures market is being used for price discovery and hedging. The pricing of oil is being determined by the futures price plus an adjustment for basis: "Although the futures exchange does not quote prices for the current month, prices for the first future month are often used as reference for prompt (current month) trades (e.g., price at the time of transfer is based on the day's 'Merc' plus or minus a 'differential')" (NPC 1989, p. 104). The use of futures pricing in oil contracts implies futures pricing will also be used in gas contracts. 
The basic economic principle is that for cases in which a competitive market price exists and is widely known, transactions will occur at this price. Transactions at long-term fixed prices or at other non-market-based prices become less feasible in competitive markets. The implementation of market-based pricing in gas contracts could, however, be retarded by the regulatory process, because of its lack of competitive pressures. Reports that the Russians use NYMEX futures prices for their own price referencing convey hope that utilities and their commissioners will not be far behind (Schlesinger 1990).

This brief review of the gas futures market and some futures market literature reveals two basic points. First, the main economic function of futures markets is to discover efficient market prices and reveal them to everyone. Second, when a futures market exists, futures prices tend to be reference prices for physical commodity transactions. 


\section{GAS CONTRACTS IN EFFICIENT PORTFOLIOS}

This section focuses on the price component of natural gas contracts and considers efficient pricing, price risks, financing capital investments and gas contracts in efficient portfolios. We discuss first the "contracts problem" that characterized the gas market during the early 1980s. The second part of this section defines the price component of gas contracts that is likely to characterize the evolving, more competitive market. Thirdly, price risks are considered in terms of whether they are reduced by purchases at fixed prices or market prices. The fourth part of this section considers the relationship between contract terms and the ability of the customer to obtain financing for capital investments. The last part of this section defines the role of fixed-price contracts in efficient portfolios.

\subsection{THE CONTRACT PROBLEM}

Until the early 1980 s, natural gas was sold under long-term contracts (e.g., 10 or 20 years), with fixed prices. Contracts with fixed prices were feasible because they were approved by utility commissioners and because there was no competitive market price for gas. There was no futures market or spot market to reveal competitive prices. Instead, extensive price regulation concealed equilibrium prices and produced inflexible prices. In this environment, fixed-price contracts appeared to ensure supply reliability at stable prices.

Wellhead prices were at historically high levels during the early 1980 s and reached a peak in 1984. With the coming of deregulation, producers and purchasers of gas expected price increases, and purchasers were anxious to lock in long-term fixed-price contracts. Instead of price increases, the average wellhead price (in current dollars) of gas supplies fell from $\$ 2.66 / 10^{6} \mathrm{ft}^{3}$ in 1984 to $\$ 1.72 / 10^{6} \mathrm{ft}^{3}$ in 1990 and subsequently decreased to about $\$ 1.00 / 10^{6} \mathrm{ft}^{3}$ (DOE 1991a, p. 177). The legal commitment to "take or pay" a minimum quantity of gas at more than double the market price put an enormous strain on purchasers that became known as the "contracts problem." One result was a renegotiation of these contracts, which required years of legal and regulatory effort. A second consequence of the contracts problem was that customers purchased gas at prices significantly above current market prices. This episode reveals first that fixed-price contracts do not ensure stable retail prices or supply reliability, and second that fixed-price contracts, when approved by regulators, shift price risks onto customers. This risk is inherent in utility regulation, and reducing it is one objective of market-based proposals.

\subsection{EFFICIENT PRICES}

Natural gas contracts written in the future will probably be for various durations, but in most contracts the prices will probably be market based and not diverge significantly from spot or futures market prices. The present structure of the gas market (Figure 1) can conduct business at minimum transaction costs with extensive use of short-term contracts. The widespread knowledge of spot and futures prices encourages the use of these prices in 
gas trades. The transactions cost model is the central framework of the large technical literature on efficient contracting. However, the terms of contracts can be influenced by other variables, such as regulation (discussed in the next section of this study) and the need to reduce price risks.

One possible relationship between contract prices and risks is illustrated by considering an industrial firm that uses gas extensively as an input in its processing. The firm is deciding on plant location and requires a reliable long-term supply of natural gas. If the firm locates where it has access to only one pipeline and a limited number of gas sellers, the firm will probably seek a long-term contract to obtain gas. Alternatively, if the prospective location affords numerous opportunities for obtaining gas, contracts are likely to be of shorter duration, and spot purchases will be made. Input supplies are most reliable in a competitive market with numerous suppliers, but, in principle, reliable gas supplies can be obtained from either location. However, the appropriate contract duration is likely to be different.

Regardless of the preferred contract duration, given the availability of market prices, the firm is not likely to desire a constant or fixed price over a multiyear period. In the case of a fixed-price contract, the market price will eventually diverge from the contract price. As illustrated in Figure 4, the market price exceeds the contract price during the third year of the contract. If the contract price were fixed, the seller would have an incentive to breach the contract, renegotiate the terms, or make a "best effort" to deliver gas that would be unsuccessful. If the contract price were to exceed subsequent market prices (as in the second year), the industrial customer would have an incentive to breach the contract, reduce demand, or switch fuels. In any case, supply reliability would be compromised. Fixed-price contracts have higher transaction costs than market-based prices because of the enforcement costs and risks of contract abrogation. These risks become serious with long-term fixed-price contracts, in cases where market and contract prices diverge significantly. The discovery of efficient prices in the futures market increases the risk of contract problems when contract prices diverge from market prices.

Market-based prices would also reveal more seasonal variations to ultimate customers than do fixed prices. If retail gas prices were to reflect market conditions on a seasonal basis, the efficiency of the gas and electricity markets would be enhanced. As depicted in Figure 4, market prices could be lower than regulated prices, such as during the summer, which would increase the demand for gas cooling technologies. DOE and the Gas Research Institute have supported the development of gas cooling technologies. The increased use of gas in off-peak summer months would add stability to the gas industry. This gas use would decrease the demand for electricity during peak periods and reduce the average cost of producing electricity.

The conservation goals of the national energy policy would be enhanced by allowing more seasonal variations in the price of gas (and electricity) to residential and commercial customers. If winter peak gas prices and summer peak electricity prices were reflected in 


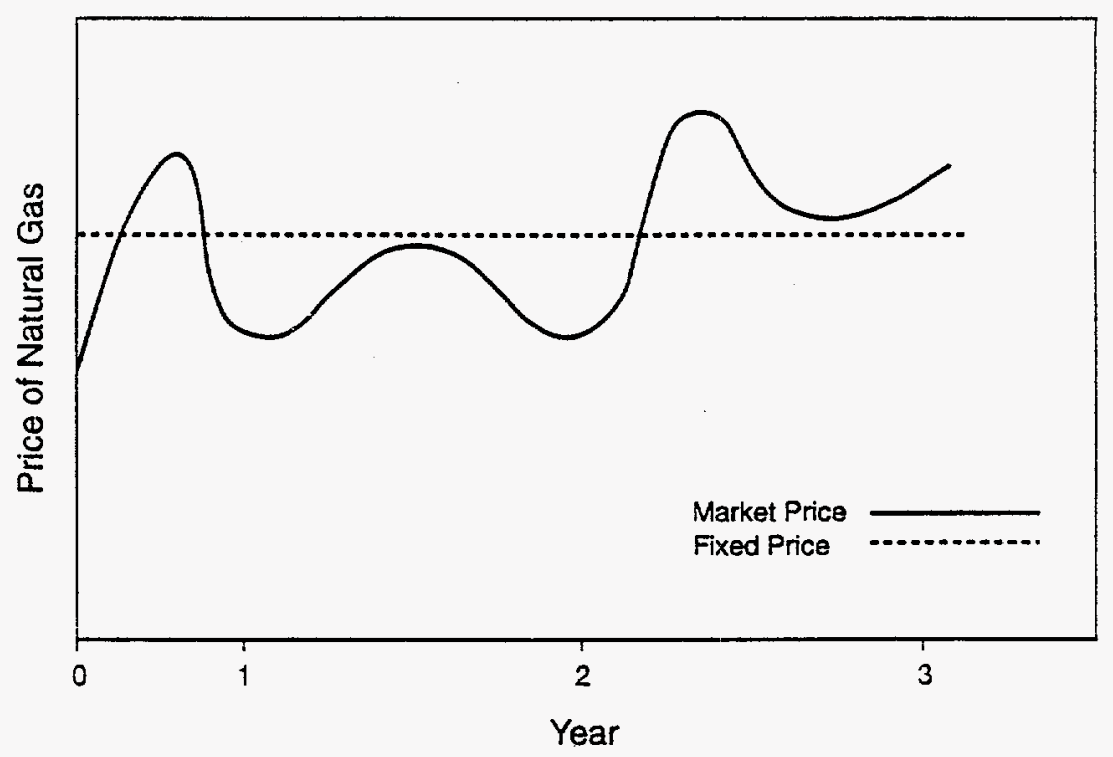

FIGURE 4 Market Prices and Fixed Prices for Natural Gas in a Three-Year Period

retail rates, customers would be encouraged to adopt efficient conservation measures. At present, the relatively low retail gas prices during the winter discourage customers from undertaking conservation measures.

Another cost of fixed-price contracts results when gas is exchanged at an economically inefficient price. ${ }^{16}$ If an industrial customer purchases gas at above-marker prices, this customer is at a competitive disadvantage compared with other industrial customers that purchase gas at market prices. If an industrial customer can purchase gas at below-market prices, it can compete favorably with its competitors. A fixed-price contract does not ensure stable profits; rather, it results in the firm becoming a fuel price specuiator. Most firms would probably obtain reliable supplies if they had a portfolio of contracts and made spot market purchases. Such a portfolio might contain contracts of various duration and some forward price contracts designed to reduce price volatility. Or a irm couid purchase at current market prices, such as spot prices and futures prices, and use the furures market to hedge against undesirable price risks. The literature on the futures market indicates that when such a market for a commodity exists, futures prices will be the reference prices for commodity transactions. When a competitive market price for a commodity exists and is widely known, transactions will occur at market prices. Competitive firms that use gas as an input are most likely to purchase gas at current market prices, as jetermined on the spot market or referenced to the futures market.

${ }^{16}$ Henderson and Quandt (1980, pp. 145-156) explain that recontracting is the mechanism by wich a market achieves an efficient equilibrium at a single price and avoids trading at disequiiiorium prices. 


\subsection{FUEL PRICE RISKS}

The central point of the above section is that spot (or futures-referenced) prices for gas are economically efficient. An alternative view, voiced by some gas marketers, is that fixed-price contracts can reduce profits or income risks of both the producer and customers. Furthermore, efficient portfolios of gas contracts would contain a mixture of spot market and forward market contracts. The next section considers the portfolio aspects of fixed-price contracts. This section reviews a formal analysis of price risks and contract terms by Polinsky (1987) and concludes that fixed-price contracts do not necessarily reduce the risks to income. Under some conditions, fixed prices increase price risk and spot purchases reduce price risk. The implication of Polinsky's analysis is that contracts designed to minimize price risk will contain fixed-price or spot-price terms, depending on the source of risk and on who is more risk averse, the buyer or the seller.

Suppose that buyers and sellers of gas were to agree on an expected future price of gas. In the absence of this concurrence, long-term contracting might be infeasible or might be feasible only at future spot prices. Suppose that price risk were defined by the variation in price and that buyers and sellers had a similar assessment of price risk. Consider the case of a gas producer, with known and constant production costs, who could obtain a guaranteed and acceptable rate of return by contracting to sell gas at a fixed price. The price risk would be on the demand side, and the producer would be assumed to be risk averse. Under these assumptions, the gas producer could obtain insurance against price fluctuations with a fixedprice contract. ${ }^{17}$

If the source of price risk were on the production (or cost) side, a different result would emerge. If future gas prices were determined by production costs, a spot price contract would insure the producer from price risks. By contracting at spot prices, the producer would be assured that market prices always reflected costs. Gas producers with existing wells have known and reasonably fixed costs and might therefore prefer contracts with stable prices. Polinsky's analysis suggests that gas producers could reduce the risks to their income with fixed-price contracts, but gas purchasers could reduce these risks with spot purchases.

The implication of Polinsky's analysis for regulatory policy of gas purchases depends on regulatory pricing objectives. If regulators wish to encourage long-term fixed prices of gas and electricity, then long-term fixed prices of gas reduce utility risk to price changes. If regulators prefer that gas and electricity prices reflect marginal costs, then purchasing gas at current spot prices reduces the utility's risk and allows customers to see efficient prices.

Suppose that an industrial customer were to contract for gas directly from a producer. Gas production and distribution costs are known and relatively constant, and the source of price variations is on the demand side. The gas producer may prefer a fixed-price

17 In the natural gas industry, production costs are largely incurred at the time the well is drilled or the field is further developed. Over time, the production costs for drilling new wells change, but the historic costs of older wells are unaffected. If the producer still wants risk protection from future price fluctuations, this producer may sign new long-term fixed-price contracts. 
contract to yield a predictable profit over fixed costs. However, the industrial customer may prefer a spot-price contract to compete with other industrial firms that purchase gas at spot prices. In this example, a spot-price contract reduces risks to the industrial customer. When the source of the price risk is demand variations, the customer reduces risk through spot purchases, whereas the supplier reduces risk by fixed-price contracts.

In Polinsky's analysis, the price term that is agreed upon in a contract depends on whether the seller is more risk averse than the buyer and on the source of risk. In general, one cannot simply observe a market and determine whether buyers or sellers would prefer fixed-price or spot-price contracts. In this gas supply example, the price risk is on the demand side. The contract between the producer and industrial customer will have fixed prices if the producer is most risk averse, but it will have spot prices if the industrial customer is more risk averse.

The Polinsky analysis appears more relevant to a one- or two-year contract than to a long-term contract of 10 years or so. In the long term, there is less distinction between supply-side and demand-side risk; hence, the preference of buyer or seller for fixed-price contracts becomes ambiguous. Also, in the long term, significant disequilibrium prices will result in contract enforcement costs and incentives to breach the contract. This characteristic of fixed-price contracts indicates that they always have a risk component not present in spotprice contracts. One implication of Polinsky's analysis is that although fixed-price contracts may reduce price risk, they are just as likely to increase this risk. Similarly, contracting at spot prices may reduce price risk in some cases but increase it in other cases. Another implication of this analysis is that portfolios in an efficient market would contain a mixture of spot prices and forward prices. This conclusion is important and supports the position of the gas marketers, who argue that efficient portfolios contain contracts with a mix of contract terms, some based on spot prices, others based on forward prices. The contribution of forward prices is to diversify some price risk and redistribute it to those who can efficiently bear it.

Examples of long-term fixed-price contracts that appear consistent with Polinsky's analysis include mortgages for residential households and other long-term fixed-rate debts, such as bonds. The residential household may prefer a fixed rate because it results in fixed monthly costs for an expense that is a large share of income. The holder of the mortgage may be a lending institution, insurance company, or pension fund. The holder can hold a diversified term structure of assets with several price components. Long-term fixed rates are feasible for a lender when the risk is diversified away. The borrower, however, pays a risk premium that typically causes long-term rates to exceed short-term rates for similar financial assets. $^{18}$

18 The preference of some households for long-term fixed-price mortgages does not imply that customers would be served by LDCs that purchased gas under similar terms. First, households in the aggregate hold a diversified portfolio of mortgages, including short-term contracts (renters); short-term mortgages with adjustable rates after, for example, three years; variable-rate mortgages; and fixed-rate mortgages. The critical point is that consumers have a choice of mortgages, rather than having this choice made for them by regulators. 


\subsection{CONTRACTS AND FINANCING}

An important issue in the gas industry is whether a long-term fixed-price contract is necessary to obtain financing for large capital investments. For instance, can an independent power producer (IPP) obtain capital without a long-term fixed-price contract for fuel? Can producers obtain financing for new wells without long-term contracts to sell gas? The history of the gas industry - and the oil industry as well - suggests that long-term contracts were required to obtain financing for capital investments. Such contracts were intended to ensure the lender of a guaranteed revenue stream that would repay the loan.

To obtain credit, a borrower must provide assurance to the lender that the loan will be repaid with a low risk of default. Contracts per se are not significant; rather, their value derives from ensuring debt repayment. When a contract provides this assurance, it has value in terms of obtaining financing; when it provides no such assurance, it has no value. Longterm fixed-price contracts had value before the contracts problem of the 1980 s. First, with a high degree of asset specificity, long-term contracts had lower transaction costs than shortterm contracts. Second, with a small number of buyers and sellers, contracts ensured a longterm business relationship. In a market characterized by rigid prices, that resulted from price controls on gas from wellhead to burner tip, long-term fixed prices appeared feasible. In the current gas market, market-based prices have replaced rigid prices, and a large number of buyers and sellers have replaced "small numbers bargaining." Under these conditions, long-term fixed-price contracts have a diminished value in assuring loan repayment.

A view that appears to be common knowledge is that long-term contracts are necessary to obtain financing from Wall Street for long-term investments in the gas industry. These investments include pipelines, exploration and development, and generating stations owned by IPPs. This view suggests that Wall Street accurately assesses information about the risk and expected return of alternative investments and then allocates capital to those investments offering the most favorable terms. The type of contract that offers the most reliable rate of return is the one allowed by utility commissioners and thereby repaid by ratepayers. If fixed prices were automatically reflected in rates, fixed-price contracts would be preferred by lenders. However, if market price contracts were allowed by regulators, these contracts would be preferred, because they would ensure a future revenue flow. For instance, a long-term contract between an IPP and an electric utility supposedly ensures that the IPP will obtain future revenues that will earn a return for the initial investors. An IPP will likely obtain funding from Wall Street if its contract with the utility is allowed by utility commissioners.

Most IPP fuel contracts have been at non-market-based prices, and Wall Street has endorsed such contracts. Wall Street does not prefer long-term fixed-price contracts per se; rather, it prefers the assurance of receiving a rate of return on investment. Utility commissioners have allowed utilities to contract with IPPs under an apparently competitive process. However, this process frequently includes fixed-price fuel purchase contracts between IPPs and fuel suppliers. The implicit acceptance of fixed-price fuel purchase 
contracts by IPPs has resulted in Wall Street funding such investments. If utility commissioners were to allow market-price contracts, Wall Street would prefer such contracts. If non-market-based prices could not be passed on to customers, Wall Street would ensure that capital investments backed by these contracts would not be financed. Given the competitive nature of a natural gas spot market and futures market as well as the large number of sellers of gas, the acceptance of these market conditions by utility commissioners would mean that fixed-price contracts would not be required by Wall Street.

As the gas market has developed since the early 1980 s, contracts have become less important in ensuring reliable supplies or sales. Because the market is characterized by a large number of buyers and sellers, spot transactions have become as feasible as contract purchases. The development of a spot market means that fixed-price contracts are not essential to the purchase or sale of gas. The development of market prices in the form of spot prices and futures prices means that most gas transactions will be conducted at market-based prices. Long-term fixed prices do not ensure a constant revenue flow. Instead, fixed-price contracts introduce the risk of breach of contract as contract prices deviate from market prices. The most cost-effective insurance to guarantee the lender a minimum revenue flow is using the futures market to hedge against an adverse price change.

The general principle suggested to relate contracts to obtaining financing is as follows: The contract terms used by buyers and sellers to most efficiently conduct business are the contract terms required by lenders to grant financing. Markets characterized by a high degree of asset specificity will rely on. long-term contracts, and such contracts will be necessary to obtain financing for capital investments. If the markets are highly regulated and have rigid prices, contracts are likely to contain fixed prices. If current market prices are widely available, contracts, even long-term ones, are likely to reflect market prices. Such contracts will be appropriate for obtaining financing. When business is conducted in a spot market, contracts will not be useful to obtain financing. For instance, a retail establishment is a capital investment, but sales to customers are solely on a spot-market basis. A lender may require collateral to finance this investment, but the collateral will not be in the form of contracts with potential customers. The gas supply industry is evolving toward a situation in which many buyers do business with many sellers at market prices. These conditions will determine the nature of gas contracts, which, in turn, will be appropriate for obtaining financing for capital investments.

The apparent difficulty in writing long-term contracts is explained by their diminished value in reducing transaction costs now because so many buyers and sellers of gas transact their business in a spot market or with short-term contracts. The recently (1990) established futures market provides an incentive not to write fixed-price long-term contracts but instead to contract in terms of competitive market prices. The market for gas purchases will - and should - evolve to a point where gas supply portfolios consist of spot purchases and contract purchases of various duration. However, the price component of the contract will - and should - be closely indexed to a market price. 


\subsection{EFFICIENT PORTFOLIOS}

The Domestic Natural Gas and Oil Initiative emphasizes a portfolio approach to gas contracting (DOE 1994). Indeed, the technical literature on efficient portfolios focuses on diversification to reduce risk. Gas producers and gas purchasers may be averse to volatile spot prices and instead prefer diversified portfolios of contracts with forward and spot prices. A forward-price contract is, in effect, a long-term fixed-price contract. The allocation of financial risk provides an additional explanation of the duration and price component of contracts. ${ }^{19}$ Gas marketers argue on behalf of diversified portfolios that would reduce risk to utilities and their customers. For instance, Enron Gas Services states that the ratio of fixed-price contracts to market-responsive contracts in prudently balanced portfolios may range from $50 / 50$ to $70 / 30$ (Wielgus 1992). In considering this portfolio perspective, it is essential to separate the interests of the utility, its shareholders, and its customers.

Consider first the interests of customers. The hypothesis is that customers would prefer the LDC diversify its portfolio by purchasing fixed-price contracts and thereby reduce price risks to customers. A crucial point is identifying the relevant portfolio. The portfolio relevant to a residential customer is that customer's own portfolio of assets. Average expenditure on natural gas in 1990 by households using natural gas was just under $\$ 500$, which is a small share of average household income. For many households the risk of gas price on the overall portfolio wealth is relatively insignificant. Gas costs can increase household portfolio risk through seasonal variations in fuel bills. The amount of gas purchased in the residential and commercial sectors during the three winter months averages about seven times greater than the amount purchased in the summer months. Stabilizing fuel prices would not benefit customers nearly as much as would stabilizing fuel bills. Most utilities have a budget billing program, by which customers can pay a constant monthly bill and settle the difference at the end of the year. For example, only about $24 \%$ of the residential customers of Baltimore Gas and Light participate in this program. Most customers do not have a strong preference for more stable monthly bills.

The significance of focusing on the customer's portfolio of total assets is that we can consider the role of fixed-price gas contracts in reducing the customer's portfolio risk. The most efficient way a customer can reduce portfolio risk (e.g., due to energy prices) is by considering all options available and then making the choices appropriate for his or her own portfolio. A customer concerned about volatile energy prices may reduce this risk by undertaking various conservation measures in his or her own household or perhaps by having backup fuel switching capability. ${ }^{20}$ Some customers may prefer a diversified portfolio of spot- and forward-priced contracts; however, the preferred mix of individual customers would not

19 Mulherin (1986) tests empirically the transaction cost, market power, and risk allocation hypotheses of contract provisions and concludes that the transaction cost model is supported and that the other models are not supported.

${ }^{20}$ If utility commissioners were to allow fixed-price gas contracts with the objective of diversifying customer risks, they would distort market signals and thereby discourage investments in energy conservation. 
likely correspond to the portfolio selected by the LDC. An LDC portfolio that contains a share of fixed prices will not efficiently diversify away risks for individual customers; first because customers prefer different portfolios, and second, because customers can more efficiently diversify away their own risks.

The portfolio hypothesis also asserts that utilities would prefer to diversify their portfolios by including fixed-price and spot-price contracts. The principles of modern finance indicate that shareholders can diversify away random (unsystematic) risk by holding a diversified portfolio of common stocks, implying that utilities should not be highly risk averse to purely random risk, because stockholders can readily diversify away this risk. Fixed-price contracts would appear to offer no significant risk reduction to ultimate customers or to utilities. However, customers should have the opportunity to select such contracts, as should utilities. If utilities reveal a preference for fixed-price contracts, then utilities - not customers - should pay for these contracts.

A view advanced by some fuel purchasers for electric and gas utilities (including Southern California Gas Company [SoCalGas]) is that fixed prices are a least-cost purchase mechanism because future prices will probably rise. Fuel purchases by utilities should never be judged to be prudent on the grounds that projecting contract prices will be lower than market prices. First, if the consensus is that prices are expected to rise, the purchaser would not be able to buy at fixed prices that are less than expected future prices. The seller would always have the option of selling at the higher prices reflected in the futures market. Second, gas purchasers made a mistake in the early 1980 s by signing long-term fixed-price contracts; a collapse in gas prices occurred later. Both common sense and historical evidence suggest that utility customers would not benefit if utilities purchase fuel at fixed prices that are expected to be below future market prices. LDCs serve their customers' needs by providing reliable service at market prices, not by being fuel price speculators with their customers' money.

Utilities have almost no chance of outperforming the market in predicting future market prices and contracting at lower prices. A massive amount of evidence from financial markets suggests that experts cannot consistently outperform the market, either by forecasting major market movements or selecting undervalued securities. The competitive conditions that characterize financial markets imply that the current value of securities reflects all available information, including an assessment of the future. Financial assets tend to be priced efficiently; however, they are subject to random and unpredictable variations. If experts in financial markets cannot consistently predict future prices, certainly fuel purchasers for electric and gas utilities cannot be expected to forecast market prices more accurately than the forecasting establishments. Utility customers are not well served by utility efforts to purchase fuel at below-future-market prices. Customers should not be forced into the position of bearing the risk of utility fuel purchasing decisions, especially when these decisions are not, on the average, in the customers' interest. The regulatory policy that is in the long-run interest of customers is simply to let the allowable cost of gas be equal to its current market price. 
Fuel price risks are generally understood simply as the risk of volatile fuel prices. However, two other fuel price risks are the risk of disallowance and the risk of disequilibrium prices. Utilities will come under increasing risk of disallowance by fixed-price purchases in cases in which the price ultimately deviates from the current market price. The risk of disallowance could be eliminated by utility commissioners who would adopt a policy to automatically accept competitive market prices. The risk of disequilibrium prices occurs when an LDC purchases fuel at a fixed price and an LDC customer has access to competitive market prices. If the LDC sells gas to such a customer at a fixed price that exceeds the market price, the customer has an incentive to bypass the utility. However, if the LDC sells gas at the market price, the customer has no incentive to bypass the utility, because this type of customer cannot purchase gas at below-market prices. Industrial and large commercial customers are served best by purchasing gas at market prices.

Natural gas and electric utilities may be inclined to purchase a share of their gas supply portfolio under long-term fixed prices to add an element of supply reliability to the portfolio. Supply reliability and price stability are separate issues. Fixed-price contracts do not enhance supply reliability and may instead compromise it by introducing contract risks. Long-term contracts may add an element of supply reliability where such contracts are likely to be fulfilled. Contracts at market prices are more likely to be honored than contracts at non-market prices. If customers reveal a preference for supply reliability above that provided by spot purchases, utilities or competitive merchants should oblige by purchasing in the spot market and paying a premium for reliability. However, such a premium should reflect customer interests and not utility interests.

Efficient portfolios of LDC contracts would include some spot purchases and contracts of various duration that minimize transactions costs. Contract prices would be referenced to the spot or futures market and customers would experience more seasonal price variability. Fixed-price contracts would be purchased only at customer directive and only those customers would see fixed prices. 


\section{CONTRACTS WITH REGULATED UTILITIES}

Gas purchases by both electric and gas utilities are reviewed by state utility commissions to determine whether the actual costs are prudently incurred. The prudence review by utility commissioners can create incentives that are different from those of a competitive market. Gas and electric utilities may each prefer long-term contracts with fixed prices. Utility commissions could approve such contracts, even though they are not economically efficient or in the interest of the ratepayer. Some of these incentives are discussed here as the principal agent problem.

The development of the spot market and futures market enables gas to be purchased at current market prices regardless of contract duration. In the absence of competitive gas merchants selling gas to ultimate customers, commissioners should base the allowable costs of purchasing gas on current market prices, regardless of actual cost. If customers reveal a preference toward alternative gas contracts, such purchases should automatically be allowed. The improvements in efficiency resulting from such a purchasing strategy are explained in Section 6.2.

Although the main focus of this report is on gas utilities, the analysis also applies to fuel purchases of electric utilities. In contrast to gas distribution companies, electric utilities have numerous fuel choices. The theme of Section 6.3 is that expected future prices and risks should be reflected in the choice of fuel, but in cases where gas is selected, the gas should automatically be priced at competitive market prices.

\subsection{THE PRINCIPAL AGENT PROBLEM}

A market inefficiency results when an individual (principal) retains an agent to act on the principal's behalf, and the agent, who has his or her own objectives, fails to represent the interests of the principal. The cause of the market failure is termed the principal agent problem. Examples are numerous: the surgeon who recommends unneeded surgery, the insurance agent who recommends that the customer purchase more insurance than is necessary, and the stockbroker who "churns" the client's portfolio.

The purchase of long-term fixed-price contracts by regulated utilities may produce economically inefficient prices and reflect the principal agent problem. The regulated firms include natural gas LDCs and electric utilities that purchase gas. The costs of purchasing gas are recoverable through retail prices if they are judged to be prudently incurred by utility commissions. Regulation is justified on the ground that it reduces the number of market failures. However, the approval of fixed-price fuel purchasing contracts by utility commissions may introduce a market failure in the form of inefficient prices. ${ }^{21}$

${ }^{21}$ Fixed-price contracts could cause a market failure, termed a negative externality. Price and quantity flexibility is the mechanism by which markets adjust to changes in supply and demand. Fixed prices reduce the responsiveness of markets and tend to increase the instability and volatility of markets. An extensive body of economics literature documents this inefficiency (Carlton 1979), although much of it relates to the labor market. 
The fuel purchasing agent of an electric or gas utility may have incentives other than obtaining economically efficient prices. For example, the purchasing agent may prefer longterm contracts, either at fixed prices or at a premium over spot prices. A successful transaction meets the responsibilities of the fuel purchasing agent because reliable supplies have been obtained. If the terms of the contract are accepted by the utility commissions, the agent has also avoided the risks of disallowance. The agent has the primary incentive to obtain reliable supplies and satisfy the commissioners. If fuel prices are later found to be economically inefficient, the agent does not pay for that inefficiency; rather, the ratepayer pays. If fuel prices subsequently fall, and customers could have had lower spot prices, the customers fail to benefit. A fixed-price contract shifts the risk of inefficient fuel prices to customers, even though the fuel purchasing agent has made the decision. A utility contract to purchase fuel at spot prices plus a premium also illustrates the inefficiency described by the principal agent problem. The appeal of such a contract to the purchasing agent is its convenience relative to competitive procurement. The cost of the premium is borne by ratepayers in the form of excessive fuel costs.

Lemon (1990) considers various gas supply portfolios characterized by the average price of gas and the risk of underrecovery by regulation. He notes that a portfolio that reduces the average cost of gas but increases the exposure of the utility to regulatory risk may not be in the utility's self interest because it does not profit from lower prices. The inefficiency caused by the principal agent problem requires the consent of the utility commissioners. Some commissioners have viewed long-term contracts at a fixed price or at a price premium as prudent investments because they appear to provide long-term supply reliability. The principal agent problem suggests a bias in the regulatory system in favor of riskless and "allowable" prices instead of current market prices. Recent evidence is that regulatory endorsement of fixed-price contracts is diminishing. However, principal agent inefficiencies are showing up in unnecessary high premiums and in LDC consideration of futures market participation.

The technical literature on contracts indicates that the duration of a contract is selected so as to minimize transaction costs between buyers and sellers. An additional hypothesis is that regulation imparts a bias in efficient contracting by encouraging contracts of longer-than-optimal duration. Long-term contracts of 10 and 20 years are observed primarily in regulated firms, such as utilities purchasing gas and coal. As noted by Palmer et al. (1993), the newspaper publishing and petrochemical industries are characterized by a degree of asset specificity similar to that of gas and electric utilities, but they have contracts that are rarely for more than five years. The principal agent problem suggests that regulated firms may prefer long-term contracts more than unregulated firms do. The extended duration may appear to provide the regulated firm with supply reliability and security, which, of course, are high priorities. The regulatory bargain gives utilities an obligation to serve, which makes supply reliability a much higher priority than minimizing costs. The utility that fails to provide reliable service is exposed to adverse publicity and the displeasure of the regulators. The utility that fails to purchase fuel at the lowest possible price can typically shift these costs to customers without being exposed. When long-term contracts contain fixed prices, the risks of price inefficiencies may be shifted to customers if the contracts are judged 
prudent by regulators (Sutherland 1990, 1993). The regulatory bias in favor of long-term contracts with non-market-based prices probably results in transactions occurring at economically inefficient prices over a long period of time.

The principal agent problem has been a major source of inefficiency resulting from utility regulation that has affected more than just gas contracts. The huge investments in nuclear power could only have been made by utilities with a regulatory bargain that shifted the costs and risks to ratepayers. The integrated resource plans of electric and gas utilities also require financial support by ratepayers. The risks of bad investments are again borne by ratepayers. Even the savings and loan crisis can be blamed on distorted incentives in the form of a principal agent problem.

The policy question is how to eliminate the principal agent problem and thereby encourage efficient contracting. The answer is simple: utility commissions need not act as agents for ultimate customers. Utilities and ultimate customers should be free to choose short-term or long-term contracts or to use the spot market. The suggested regulatory change under the best option is to allow gas merchants open access to LDC pipelines and the opportunity to contract directly with ultimate customers. The second-best option is to encourage LDCs to offer a menu of contract choices to ultimate customers and let customers determine what is economically efficient. Under the second-best option, allowable fuel expenses would be determined by the revealed preferences of ultimate customers. Third party access would directly meet the needs of those customers served by the third party; however, a significant benefit is the discipline imposed on LDCs and the resulting benefit to LDC customers. Such customers would see competitive prices if they could readily exit the LDC and buy gas from merchants. The freedom of LDC customers to choose their own gas supplier reduces the need to regulate LDC gas purchase prices.

\subsection{FUEL PURCHASES}

Under the current regulatory regime, in which LDCs are franchise monopolies, utility commissioners should allow a process in which the "prudent" fuel price would always be determined by competitive market prices or by customer-revealed preferences. To the extent that current market prices are selected, the most likely form of this process would be a competitive bidding system, in which contract prices would be referenced to spot or futures market prices. A competitively determined "basis" should also be feasible for most locations. Alternatively, the utility and its PUC might prefer to use spot prices from one of the regional spot markets. Hatcher and Tussing (1992) argue that the appropriate location for the transaction of gas is the city gate of the LDC.

Regardless of the pricing process selected, customers would always have the opportunity to pay market prices. Gas and electric utilities would be free to engage in any fuel purchasing practices that they choose. However, prudent fuel prices would always be judged to be market prices. Utilities may prefer to competitively procure fuel at market prices, and they would experience neither profits nor losses from so doing. Utilities might prefer instead to purchase fuel under contract, at prices they expect to be lower than future 
market prices. Or utilities might choose to invest in storage or even participate in the futures market. Any of these business decisions would be considered acceptable, and all profits and losses would be received by stockholders. Eliminating the risk of disallowance to utilities would be one advantage of market-based pricing. Eliminating the risk of bad business decisions (in the form of disequilibrium prices) being shifted to customers would be the second advantage of market-based pricing.

A process that requires an $\mathrm{LDC}$ to account for fuel costs at contract terms selected by customers or by current market prices would improve economic efficiency. This proposal would eliminate five limitations with the current regulatory system. First, there is no inherent market imperfection in purchasing gas that requires regulation. Second, regulation can introduce a market failure in the form of a principal agent problem. Third, current fuel purchasing practices can result in fuels being used inefficiently because contract prices deviate from market prices. Fourth, the utility now exposes customers, not shareholders, to fuel price risks, a situation that should be reversed. Fifth, the preference of LDCs toward long-term fixed-price contracts is an inefficient mechanism to obtain supply reliability and the preferred level of price stability. These five points are described in more detail in the following paragraphs.

- There is no market failure requiring regulation and a prudence review of the fuel purchasing decision. The market failure that characterizes electric and gas utilities is the natural monopoly, or declining average costs associated with distribution. Certainly, this market failure provides no rationale for regulation of fuel purchases or for restricting entry by competitive gas merchants.

- Regulation may introduce a market failure in the form of a principal agent problem. As explained above, the LDC may have an incentive toward long-term fixed-price contracts that are not economically efficient but are in the perceived interests of the utility. If a utility is making a fuel purchasing choice - an economically efficient purchase with some risk of disallowance or a higher-cost purchase with less risk - the utility has the incentive to avoid risk.

- The economic function of a market-price system is to send the correct signals to market participants so that economically efficient decisions are made. Price flexibility is the mechanism by which a market economy operates. Market-based gas prices would send the correct seasonal and long-term signals to customers and allow them to make appropriate technology choices and fuel utilization decisions.

- Economic efficiency is enhanced when customers pay current market prices for fuel, a situation which is now feasible in the natural gas market. The LDC or electric utility should be allowed to reflect stockholder interests by making any purchasing decisions it chooses, with the caveat that customers always pay current market prices. The 
stockholders should bear the risks of any deviation between contracted fuel prices and market prices. The utility could speculate by signing fixed-price contracts in anticipation that the future market price will exceed the fixed price. If the utility speculates profitably, the stockholders would benefit. If market prices fall below the contracted price, however, stockholder dividends would be reduced accordingly. Fuel purchases, other than at market prices, should become an unregulated business, just like any other business.

An illustrative case is an effort by SoCalGas to seek approval of five long-term contracts for gas (Barnett 1991). The contracts averaged more than 10 years in length and had an estimated gas purchase value of more than $\$ 2.5$ billion. The price terms of the contracts varied, but they could be considered fixed prices with escalator clauses and, in general, not equal to spot prices. The expressed motivation of SoCalGas for entering into these contracts was to ensure long-term supplies to its core customers. The obligation to serve and the need for supply reliability were emphasized repeatedly. SoCalGas also argued that if market prices were to rise significantly, as it expected them to do, the contracts would reduce costs to customers. However, if prices would fail to rise, customers would have to pay a premium above spot prices.

The decision of the administrative law judge was to reject each of the five contracts (Barnett 1991). Judge Barnett did not object to the duration of the contracts; the main factor for the rejection was that each of the five contracts carried a price premium over spot prices. The assurance of reliable supplies may motivate a premium, but assured long-term demand is an equally strong motivation for a producer to accept a discount. According to Judge Barnett (1991, p. 27), ". . as long as public utility commissions permit LDCs to lay off their costs on the ratepayers dollar-for-dollar, there is not the kind of competition that will result in a true market price. LDCs do not have to live with their bad contracts; it is the ratepayers who live with them." This quote confirms the contention that utilities do not always have the same incentives as their customers in terms of fuel purchases. The judge also notes that some utility commissions may have a motivation similar to that of their utilities in their preference for long-term contracts and their willingness to pay a premium to get them.

The decision is consistent with the recommendations of this study. Long-term contracts are not objectionable, but requiring customers to pay fixed or escalated prices is not warranted, even if such prices are 
ultimately lower than future market prices. ${ }^{22}$ Utility negotiators may be willing to pay a premium over spot prices, as explained by the principal agent problem. This premium is probably not competitive, although gas producers certainly disagree. Rather than judge whether a premium or discount is an efficient price, the recommendation here is that utilities be allowed to price gas at market prices. In this way, the LDC, not the ratepayer, has to deal with the consequences of bad contracts. The use of market-based prices that are revealed by the futures market and adjusted to reflect actual delivery conditions would ensure competitive prices to customers and obviate the need for regulatory review.

- A view widely held in the gas and electric utility business is that reliable supplies and stable prices can be obtained only through long-term fixedprice contracts. The history of the gas industry during the early $1980 \mathrm{~s}$ refutes this view, since long-term gas contracts were breached when market prices fell below long-term contract prices. Long-term fixed-price contracts do not ensure reliable supplies. In the current gas industry, with widely available market prices, if the contract price of gas deviates significantly from current market prices, the probability of breach of contract increases. A long-term contract may contribute to supply reliability if the exchange price follows market prices. If the price component of the contract results in a deviation from future market prices, a long-term contract may reduce supply reliability. Assurances of supply reliability derive from the incentives of competition, in which a large number of suppliers can sell to a large number of buyers.

The preference of the gas industry (including LDCs) for long-term gas contracts is explained partially by the market structure that prevailed until the last few years and by the principal agent problem. When pipeline firms performed the merchant function, they were often the only (or one of a few) purchasers of gas from several producers. The producer needed a long-term contract to ensure a reliable market and reduce the transaction costs of frequent negotiations over the lifetime of the well. Similarly, when the pipeline was one of only a few sellers in the market at the distribution end, a long-term contract was again used to reduce subsequent transaction costs and risks of opportunistic behavior. As pipeline services became unbundled and pipeline companies became contract carriers, a large number of producers obtained access to a large number of distributors. Because the market is becoming one in which several sellers deal with several buyers, the value of long-term contracts

22 Fixed-price contracts would potentially enable the purchaser to obtain gas at below-market prices, a condition that is also economically inefficient. Artificially low prices for fuel discourage conservation efforts and are just as inefficient as prices that are above market prices. 
has diminished. The asset specificity of gas producers and gas purchasers dealing with a single pipeline company, and with it the value for long-term contracts, has diminished. The motivation of utilities to sign long-term contracts with a price premium is a consequence of rateof-return regulation, in which the long-term contract apparently contributes to the utility's need for price stability and supply security. The lack of incentives to minimize costs and the willingness to shift bad contracts to customers is the principal agent problem.

\subsection{ELECTRIC UTILITIES}

The primary focus of this study is on natural gas utilities; however, much of the analysis applies to electric utilities. A gas utility has no choice but to purchase gas to meet customer needs. ${ }^{23}$ If gas prices rise sharply or are highly volatile, the LDC passes these prices on to customers. However, electric utilities have some fuel-switching options as well as an initial fuel choice. Fuel choice options do not complicate the above analysis. Electric utilities may be concerned that a long-run price increase in natural gas may make it uneconomical. Electric utility commissioners may share this concern. In addition, gas prices could be assessed to be risky, that is, subject to large fluctuations. These concerns should be resolved before a fuel technology choice is made. After this choice is made, gas (and other fuels too) should be priced at market-based prices. A case cannot be made that noncompetitive prices should be allowed by regulation when competitive prices are readily available. A case for disallowing competitive prices also cannot be made, because the reason for regulation is to reduce market failures and attempt to achieve competitive results.

One approach that electric utilities have used to reduce risk is to contract with IPPs under an apparently competitive procurement system. Electric utilities obtain bids from several potential power producers and then select the preferred bidder. The selected IPP and the electric utility then enter into a long-term contract in which the IPP sells only to that utility. Although contractual terms vary widely among utilities, the availability of long-term, reliable fuel supplies is often a critical variable in selecting an IPP. The IPP must therefore enter into a long-term contract to secure fuel. The price component of the fuel contract varies among IPPs. The fuel price may be escalated at a constant rate, linked to a price index, or fixed with periodic adjustments. The agreed-upon price is not typically a market-based price but is a relatively inflexible price.

The regulatory system imparts a market distortion in the contractual terms for purchasing fuel. The market imperfection occurs when long-term and non-market-based prices are used in IPP fuel purchasing contracts and these prices are approved by regulation. Utilities shift price risk to IPPs by requiring long-term fuel contracts at price terms that insure the utilities against large price increases. IPPs obtain such contracts by paying a

${ }^{23}$ Gas utilities have options that include various demand-management strategies, but they cannot switch fuels. 
premium above market prices. The result is that fuel is purchased at non-market-based prices and the entire process is approved by regulators. An effect of procuring power through IPPs (under current regulatory incentives) is that non-market-based fuel prices are disguised within a process that may be viewed as competitive.

The regulatory bias resulting from encouraging fuel purchases at disequilibrium prices can be conveyed by comparing fuel purchasing practices under regulation with those under a competitive market. Such a market could be imagined to be a large regional grid, in which each power producer sells into the grid and all generating plants are dispatched according to marginal costs. In this hypothetical, competitive world, electric utilities would be motivated to make efficient choices. If a utility were to contract for gas at a price that later exceeded its market value, the generating unit would not be dispatched. If the contract price of gas were to be less than the market price, the unit would be dispatched, but at a competitive market price for electricity. The utility would make a profit from its good fortune as a fuel price speculator. In a competitive spot and futures market, a utility cannot consistently contract for gas at below-market prices. If the electric power market were competitive, the utility would soon learn that its best fuel purchasing strategy would be to simply buy at current market prices by using competitive procurement strategies, and the cost of electricity would reflect this price. Long-term contracts with fixed prices for fuel would not exist in a competitive market, especially one with spot and futures markets.

Electric utilities have typically purchased coal under long-term fixed-price contracts, and such contracts have been alleged to be efficient. Coal is significantly different from gas in that it is a heterogeneous commodity, differing not only in sulfur content but in other chemical properties. When a generating plant is designed to burn a specific coal that is available from one or a few sources, asset specificity suggests that the contract be long term. In some markets, numerous generating plants can obtain coal from several sources, and there is no asset specificity. In such markets, contracts are typically shorter term, and spot transactions are frequent. Where long-term contracts have had fixed prices, a contract problem has occurred, just as it has in the gas industry. A DOE Energy Information Agency study of coal contracts (DOE 1991b) indicates that fixed-price coal contracts signed in the early 1980 s became untenable as coal prices subsequently fell. The EIA study notes that contracts were bought out by utilities. These contracts used fixed prices because utilities preferred the apparent absence of risk and because commissioners allowed them. The costs of buying out the contract were no doubt shifted to customers. Contracting at market prices would have been more efficient and in the customers' interest. ${ }^{24}$

A possible concern over passing through gas purchases at competitive prices is the fuel choice bias in favor of gas. Furthermore, gas prices may be expected to rise over the long run and be highly volatile. One proposal is to automatically let competitive purchases of all inputs be allowed as prudent expenses. The electric utility would then have an incentive to

${ }^{24}$ Contracting at current market prices is not as feasible for coal as it is for gas because coal is not a homogeneous product, the coal market has a high degree of asset specificity (Joskow 1987), and the coal market does not have highly developed spot and futures markets. 
make competitive purchases and least-cost choices among technologies. Another solution to the problem of fuel choice bias is to allow the appropriate expectations to be reflected in the initial fuel choice and then allow competitive prices regardless of their level. If the accepted forecast were that gas prices will rise relatively quickly, expected life-cycle costs for gas units would also be high. The solution would be to select another fuel. If gas prices were viewed as being highly risky, electric utilities could diversify fuels and move away from using the risky fuel. Electric utilities could be encouraged to make their initial fuel choices with the same incentives as those found in a competitive market. A regulatory system is limited in its ability to impart the correct incentives for selecting fuels, especially when regulators are averse to the same risks as electric utilities. If electric utilities made more extensive use of a grid, they would have more incentive to make the best possible fuel choices.

Efficient portfolios of fuel purchases could be obtained in a generating market with numerous competitors. The best option is to encourage the development of IPPs and provide them with access to the transmission grid. ${ }^{25}$ If IPPs were to sell to a grid on the basis of competitive electricity prices, their fuel purchasing strategies would change. IPPs would require a reliable supply of fuel, which they could obtain on the spot market or through contracts of various duration. However, the fuel price would certainly be a market-based price and not a long-term fixed price. The IPP could hedge against some spot-price volatility by making futures contracts or contracts at nonspot prices. The implication is that an efficient portfolio of fuel purchasing contracts would not necessarily contain $100 \%$ current market prịces.

During the 1970 s and early 1980 s, pipeline companies signed long-term fixed-price contracts for gas with large take-or-pay provisions that resulted in minimum bills to customers. Because gas prices were expected to rise following deregulation, fixed prices appeared to be a good investment. However, gas prices fell sharply throughout the 1980s. Gas pipeline companies were locked into take-or-pay commitments at prices significantly above market prices. This problem became known as the contract problem. The risk of breach of contract is one of the major risks that market-based pricing is intended to eliminate.

A similar problem is occurring with electric utility purchases of gas under contracts based on non-market-based prices. The development of the IPP market does not solve the problem of purchasing fuel at non-market-based prices, it simply disguises the distortion. If electricity were suddenly sold in a competitive market, some gas contracts would be voided, and others would provide windfall profits. In the absence of a competitive price for electricity, the contract problem is being borne by users of electricity.

Gas and electric utilities could purchase gas at market-based prices as revealed by the spot and futures markets. Utility commissioners have recently encouraged spot-market purchases because of low spot prices. The wide dissemination of futures prices and their

25 The 1992 energy bill allows IPPs to sell directly to the grid. The author (Sutherland 1990) recommends this policy action. 
acceptance as competitive prices would be difficult for utility commissioners to ignore. Any consumer advocacy group can contrast utility purchase costs of gas with those published in the newspaper and note the discrepancy. If the utility signs a gas purchase contract at nonmarket-based prices, the purchase price will at some point exceed the published market price. The utility will then have to explain its purchase at an above-market price. For example, consumer advocates in California have alleged that Pacific Gas and Electric overpaid Canadian gas suppliers more than half a billion dollars and that customers should be refunded accordingly. The alleged cause is that the company ". . had no incentive to fight the producers because until recently it could pass on higher costs to California ratepayers" (Marshall 1992). This lack of incentive is developed in this report as the principal agent problem. The "discovery" of competitive market prices by the futures market ensures that the California experience will be repeated. As more of these cases occur, utilities and their commissioners will also discover the value of competitive market prices. The purchase of gas at market-based prices reduces two major risks that are characteristic of utility regulation: the risk of a bad business decision, in which the costs are borne by ratepayers, and the risk of subsequent disallowance by PUCs.

Some of the conclusions of this study are illustrated by considering the policy recommendation that utilities solve their gas supply problems by purchasing gas in the ground. Presumably, customers would benefit by having reliable long-run supplies and would have hedged against future gas price shocks. Clements and Graeber (1991, p. 39) comment on this strategy with respect to nonutility generators (NUGs): "The most straightforward solution to this dilemma involves the purchase of gas reserves by the NUG for specific project requirements." This solution would make essentially no contribution to the reliability or price guarantee issues. If supplies can be obtained reliably on the spot market, owning gas does not enhance reliability. In those markets in which spot purchases may be adequately reliable, short-term contracts would suffice. Owning gas in the ground is a hedge against future price increases, but it exposes the NUG to the risk of decreasing gas prices. Utilities meet some of their customer needs by supplying electricity with the appropriate degree of reliability at a minimum cost. Purchasing gas in the ground contributes to neither objective.

The main issues in this gas purchasing strategy involve pricing. This study concludes that electric and gas utilities should have the option of purchasing gas in the ground and earning a profit or loss on this investment for their stockholders. Fuel price speculation should be undertaken as a business decision, not with the objective of affecting consumer prices. Customers should pay current market prices, not artificially low or high prices that result from price speculation. In the early $1980 \mathrm{~s}$, the common expectation was that gas prices would rise because of deregulation and a shortage of reserves. Instead, gas prices declined throughout much of the $1980 \mathrm{~s}$. Customers would not have been well-served by a gas purchasing strategy in the early 1980 s, just as they were not served by fixed-price contracts.

Customers can hedge over the short run by participating in utility-sponsored annual averaging billing programs. The most efficient hedge against long-term gas price increases 
is to purchase an equity interest in gas reserves, which is done by purchasing common stocks in corporations whose major asset is gas reserves.

Utilities may prefer a portfolio of spot market and contract purchases, in which the contracts are of varying length. The appropriate duration of contracts would depend on the number of potential gas suppliers. The choice of purchasing at spot prices or contract purchasing and the duration of the contract would be left to the utility. However, regardless of the duration of the contract, the price component should reflect current market prices. The duration and price components of the contracts would be considered separately. 


\section{POLICY PROPOSAL}

This report focuses on issues related to contracts for the purchase of natural gas. However, it offers a conceptual design for regulatory changes to improve the efficiency of the distribution system. The following proposal is intended to contribute to the efficient supply and use of gas and eliminate some imperfections in the current market. One objective is to encourage efficient pricing in gas contracts. However, broader objectives include minimizing gas procurement costs, offering customers (and potential suppliers) more choices, creating stronger incentives to innovate with new technologies, and encouraging efficient retail prices. The gas market is currently resolving issues concerning fixed-price contracts in a manner indicated by this report. The main issue has become utility regulation.

There are several complicated issues associated with utility regulation: long-term fixed-price contracts, futures market participation, energy conservation programs, stranded assets and nuclear power, to list just a few. Technical arguments, both pro and con, are advanced to support one position or another. However, what is fundamentally at issue is not economic or engineering merits, but rather cost-of-service (COS) regulation. Long-term contracts are defensible if freely selected by buyer and seller. The issue is whether such contracts should be forced on customers through COS regulation. The futures market is used by numerous participants to shed price risk. At issue is whether gains or losses by LDC participation should be passed on to customers as a COS. Participants in the futures market select the position they wish to take. Under COS, the customer would be forced to pay for a position selected by the LDC that would presumably reflect the interests of all customers. ${ }^{26}$ The controversy about stranded assets is also a regulatory issue, because the issue does not arise in competitive markets. Several issues characterizing LDCs (and utilities in general) are about investment choices. Investments made by individual customers on their own behalf are rarely controversial. The inefficiency arises when investment choices that supposedly represent the interests of all customers are made by a regulated firm and these investments are judged to be a prudent COS.

To avoid these regulatory imperfections and to achieve a more efficient use of gas, the following general policy is suggested:

All participants in the gas industry - producers, industrial customers, electric and gas utilities, and ultimate customers - should be able to sign any contracts they prefer, provided they are held accountable for the contractual terms. Gas merchants and other providers of gas services should have access to ultimate gas customers through LDC pipelines and be able to offer a selection of contracts for gas and energy services. Customers remaining with their LDC should have a menu of choices,

${ }^{26} \mathrm{LDC}$ participation in the futures market is becoming of increasing interest to utility commissions with little realization that the issues have already been debated under the topic of long-term contracts. 
including the purchase of gas at current market prices obtained with competitive procurement.

This recommendation requires regulatory changes that would unbundle the services of LDCs and allow competitive access to LDC pipelines. The details of an unbundling proposal are complicated and are the subject of additional work. We simply recognize that an alternative regulatory framework could provide reliable gas supplies at market-sensitive prices and improved services to customers.

Even with third party access to LDC customers, LDCs may continue serving many of their current customers. Utility commissions could adopt a policy in which allowable fuel costs would be determined by a price cap at the city gate or by competitive procurement. The price cap approach would eliminate any unnecessary premium, and it could result in marketsensitive prices. Alternatively, the LDC could purchase a share of its gas under competitive procurement, and the resulting price could be used as a "yardstick" to judge the reasonableness of direct LDC purchases. Both the price cap policy and the yardstick approach contain improved incentives over the current cost approval system.

Some advantages of competitive procurement are as follows:

- Utilities have had an incentive to use long-term contracts and been willing to pay nonmarket prices (such as fixed prices or a high premium above market prices) for gas because such contracts have met their need for a reliable gas supply and because the costs at above-market prices have been shifted to customers. This inefficiency, called the principal agent problem, would be eliminated if market-based prices were charged to ultimate customers. The price system would be able to send efficient signals, and customers could thereby make appropriate fuel utilization and technology choices.

- PUCs would have difficulty in disallowing market-based prices, even if they rose abruptly, because such prices are widely recognized to be efficient and because other purchasers would be paying the same prices.

- The risk of bad business decisions being shifted to customers would be eliminated.

- The contract problem, resulting in breach of contract due to disequilibrium prices, would be eliminated.

- Utility customers would not be put at risk to purchase gas at inefficient prices or guarantee contracts in which prices would exceed market prices. 
- If third party suppliers were successful in attracting some LDC customers, then LDC purchasing would require less regulatory oversight.

Utilities would have the option to sign contracts of any duration they prefer and with any price component they prefer. However, in the absence of competitive sellers or revealed customer preferences for forward prices, gas would automatically be priced at current market prices. A limitation of this proposal is the difficulty of determining the exact market price that should be allowable, because the options include the futures market plus perhaps alternative regional spot markets. The preferred option of allowing competitive merchants access to LDC pipelines would enable the market to solve this problem.

A major difference between the preferred and second-best (e.g., price caps) policy options is that the preferred policy would offer gas customers the option of purchasing a diversified portfolio of contracts for gas (and gas services) that could best meet their needs. The second-best option might limit ultimate customers to making spot purchases or to fewer opportunities than the number provided by gas merchants. In particular, gas merchants could supply contracts for energy services, which would reduce the need for least-cost planning by LDCs. Even in cases where LDCs would offer customers opportunities for spot purchases and a limited selection of forward prices, it appears that the possible inefficiency would be much less than that resulting from the principal agent problem. First, the main component in retail gas prices is transportation and distribution costs, and portfolio diversification can only affect the variation of wellhead prices. Second, LDCs typically offer budget billing programs that "smooth out" seasonal variations in monthly gas bills. The main cause of variation in monthly gas bills is variation in gas purchases, not in wellhead prices. Third, if customers preferred prices other than spot prices, LDCs could expand their offerings of such contracts. Fourth, customers concerned about gas price risks could take their own defensive measures. If there were truly a market for diversifying gas price risks away, marketing firms or insurance companies could sell financial instruments that would perform this function. One of the major benefits of gas marketers having direct access to ultimate customers is price competition. A second potential benefit is that competitive energy service companies would allow for the most efficient use of energy. Such companies would certainly be more efficient than LDCs that attempt to save energy by reducing the demand for their own product.

Industrial and other unregulated customers would not have to be encouraged to sign contracts with any particular price or duration terms. In the absence of market failures, contract terms agreed to by producers and unregulated firms would be reasonably efficient. Unregulated firms in the aggregate might prefer a diversified portfolio of contracts that would include spot purchases and contracts with varying price and duration components.

A utility might wish to use a gas marketer to obtain gas under contract prices that avoid the volatility of monthly spot prices or futures prices. However, if a utility wants to reduce price volatility, either in its own interest or in the interest of its stockholders, the allowable cost and price to the customer should be the monthly market-based price, not the 
contract price. Those customers who reveal a preference for prices more stable than market prices should have their needs met by the LDC, and those customers should pay for the insurance premium.

If the recommendation to automatically price gas at market prices were to be accepted by utility commissioners, electric utilities would sign gas contracts with a duration of their choice with an assurance of reliable gas supplies. If regulators recognized the ease with which competitive prices would be discovered, they would be likely to endorse this recommendation. However, utility executives might require a bit more persuasion. Why should an industry that is primarily interested in reliable supplies (of physicals) at stable prices be interested in a paper market with volatile prices? Just as market analysts have consistently seen the value of futures-market pricing for gas contracts, officers in regulated utilities have just as consistently been unimpressed with the futures market. In October 1990 (Public Utilities Fortnightly), 15 utility executives addressed a series of questions, including some that dealt with their gas purchasing strategy with the startup of the futures market. None of the executives had an interest in participating in the market, and none mentioned basing contract prices on futures prices. Ellis (1991), a utility commissioner, observed that the regulatory community has little experience in dealing with the gas futures market and further observed that LDCs are likely to perceive regulatory and market risks that would deter their participation in this market.

The utilities and their commissioners can be reassured that using futures-market prices in gas contracts does not require participating in this market or even understanding it. Further, if the utility uses the services of a gas marketer, the marketer can effectively use the futures market without the utility's awareness. Numerous students of the futures market have observed that when such a market exists for a commodity, contracts for that commodity will contain prices referenced to the futures market. Given the inevitability of futures prices being used as reference prices, a utility that uses competitive procurement strategies will have prices that are also competitive.

A sensitive issue in the gas industry is whether gas traded under a long-term contract should include a premium above spot prices or perhaps be discounted below spot prices. Gas producers, who naturally favor the premium, note that they are providing longterm, reliable supplies, and they further note that transaction costs are lower to the purchaser than they would be if frequent spot purchases were made. The buyer, in turn, is offering a long-term, reliable demand for the gas at reduced transaction costs, and such terms should merit a discount. A price premium or discount is likely to be small and even eliminated by competition. If the basis for adjusting futures prices to cash prices is determined by use of competitive procurement practices, the problem of premium prices or discount prices is automatically solved and should not be a concern to regulators or policymakers.

One explanation for the inability of utilities to obtain long-term contracts is that they cannot agree on terms that are suitable to producers. Utilities prefer long-term contracts at current low prices with relatively low escalator clauses. Gas producers expect prices to rise 
and are unwilling to make long-term commitments at below-market prices. Basically, utilities and producers fail to agree on future competitive prices. Second, producers tend to demand a premium over spot prices for their gas, whereas purchasers prefer discounts below spot prices. Divergent price expectations and adjustments above and below market prices are not a market failure or a reason for government concern. When futures prices become widely accepted in the gas market as being competitive market prices, contracting will not be impeded by divergent expectations. Producers and utilities will be able to sign long-term gas contracts in which the price for the monthly purchase is referenced to the Henry Hub price (as determined in the previous month) or perhaps determined in one of the regional spot markets.

The purchase and sale of gas have been impeded by an inability to obtain suitable transportation arrangements. Electric utilities may not be able to obtain economical access to firm transportation on U.S. pipelines by which to move their supply from the wellhead to the plant or city gate. Transportation problems include the lack of the firm transportation that permits flexibility in receipt points and alternative delivery points in periods when the supply is not needed. The inability to resell pipeline capacity associated with this supply when it is not needed also contributes to making contracts for gas expensive. Two other contractual impediments are (1) the inability of gas producers to gain equivalent firm access to the U.S. pipeline grid to sell into New England (compared with, for example, producers in Alberta and their use of TransCanada Pipeline) and (2) the ability of Canadian producers to accept a lower long-term average price and guarantee a high reserve-to-production ratio.

The use of futures-based prices in gas contracts means that gas prices will respond immediately to changing market conditions and send a signal to market participants. Production and consumption decisions will respond much more quickly to changing market forces than they would respond under a regime of long-term fixed-price contracts. The gas market is currently depressed because gas prices have fallen significantly since the early 1980s. The market will eventually turn around as production is reduced and consumption increases. The rate at which the gas market recovers will be accelerated by gas prices that respond immediately to market forces and are revealed in the futures market. ${ }^{27}$

27 Verleger (1988, p. 377) notes that prices in oil contracts throughout the country are now referenced to the oil futures market. Consequently, this market tends to move from one equilibrium to another more quickly. Another implication of Verleger's observation is that the gas market would adjust to changes in market conditions more quickly if the market relied on spot prices rather than longterm fixed prices. 


\section{CONCLUSIONS}

The main conclusion of this study is that contract issues are appropriately resolved through a broader competitive-regulatory framework that allows customer choice, including choice of alternative suppliers. However, contract issues have been so contentious for such a long period that a summary of contract issues is provided here in the form of answers to nine key questions.

Question 1: Are long-term contracts necessary to ensure reliable gas supplies?

Answer: No. In the present market, in which a large number of gas suppliers have access to a large number of buyers, long-term contracts are unnecessary for supply reliability. - Because there is open transportation access, the natural gas market has become like other competitive markets (such as markets for consumer goods like gasoline), in which long-term contracts are almost never used and supplies are reliable.

Question 2: Did long-term contracts ever contribute to supply reliability?

Answer: Yes. Before the mid-1980s and before open transportation access, producers sold to pipeline companies and pipeline companies sold to large customers. The high degree of asset specificity necessitated long-term contracts to protect the large investments and ensure supply reliability.

Question 3: Are long-term contracts likely to make a return as a common business practice?

Answer: No. Open transportation access has permanently changed the structure of the gas market and the need for contracts. However, a decrease in the share of spot purchases and an increase in short-term contracts of one to five years are probable. Some long-term contracts may reappear, but they will most likely be at market-based prices.

Question 4: What is the significance of the gas futures market for the purchase and sale of gas?

Answer: Futures markets discover and convey efficient market prices. Gas prices can be referenced to futures prices. The wide dissemination of competitive market prices makes transactions at fixed prices economically inefficient and much less feasible than they were in years past. Regardless of the duration of gas contracts, the price term is likely to be market based and probably referenced to the futures market or the spot market.

Question 5: If utilities could purchase gas under fixed-price contracts, would price risks be less than if gas were purchased at competitive market prices? 
Answer: Probably not, since fixed-price contracts have the risk of disallowance by utility commissioners when contract prices exceed market prices that are now widely disseminated. Fixed prices introduce risks of contract breach and buyout and also of bypass by large customers who can purchase gas on the spot at competitive prices. A serious inefficiency in the regulatory process is the shifting of risks to utility customers.

Question 6: Should electric and gas utilities be permitted to sign fixed-price contracts or invest in gas in the ground?

Answer: Investor-owned utilities are private businesses owned by stockholders and should be permitted to make these investments as they see fit. Any deviation between gas costs from these investments and competitive market prices should be passed on to stockholders. Allowable gas prices should always be determined by competitive market prices, which are now widely known.

Question 7: Would long-term fixed-price contracts for gas assist independent power producers in obtaining financing for their generating stations?

Answer: A change in the attitude of Wall Street is predicted. Financing IPPs will require reliable fuel supplies at competitive and allowable prices. In cases where spot purchases and short-term contracts provide reliable supplies, they should also satisfy Wall Street. Competitive fuel prices rather than fixed prices are likely to convey a reliable rate of return on investment. When utility commissioners endorse competitive prices rather than fixed prices, Wall Street will make similar financial commitments. Gas marketers may construct financial packages that include forward price contracts and assist IPPs in obtaining financing.

Question 8: Would long-term fixed-price contracts contribute to exploration and development of new gas reserves by independent producers?

Answer: New investments in gas reserves require higher gas prices, not contracts at fixed or market prices. When gas prices rise, independent producers requiring external financing will obtain financing, but not under fixed-price contracts. Gas producers have an implicit long-term contract because they are able to sell their gas over the long term at market prices.

Question 9: If gas is to compete with coal in the market for new generating stations, will gas require coal-type (long-term fixed-price) contracts?

Answer: No. The incentive to use market-based pricing is stronger in gas contracts than in coal contracts because gas is a homogeneous and fungible commodity and particularly because a competitive market price is discovered and revealed in the futures market as well as in various regional spot markets. The existence of efficient prices makes the use of 
inefficient prices infeasible. The contract problem with coal contracts signed in the early 1980 s suggests that coal contracts will probably move to more market-based prices. There

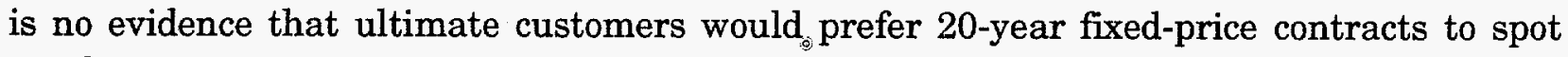
purchases. 


\section{REFERENCES}

Barnett, R., 1991, Proposed Decision of ALJ Barnett, Public Utilities Commission of the State of California, San Francisco, Calif., April 26.

Blair, R.D., and D.L. Kaserman, 1983, Law and Economics of Vertical Integration and Control, Academic Press, Inc., Orlando, Fla.

Carlton, D.W., 1979, "Contracts, Price Rigidity, and Market Equilibrium," Journal of Political Economy 87(5):1034-1062.

Clark, N.E., and G.W. Clark, 1984, Governments, Markets and Gas, Energy, Economics and Environment Institute, Arlington, Va.

Clements, J., and D. Graeber, 1991, "Dealing with Gas Uncertainties," Power Engineering, pp. 37-39, April.

Coase, R., 1937, "The Nature of the Firm," Economica 4:386-405, Nov.; reprinted in G. Stigler and K. Boulding (editors), 1952, Readings in Price Theory, published by R.D. Irwin, Homewood, Ill., pp. 331-351.

Dearborn, N.W., 1990, "The Developing Natural Gas Futures Market and Its Potential Impact on Domestic Natural Gas Markets," Natural Gas Monthly, U.S. Department of Energy, Energy Information Administration, Washington, D.C., pp. 1-21, March.

DOE: See U.S. Department of Energy.

Ellis, D.J., 1991, "Futures Trading in the Natural Gas Industry from the Regulator's Viewpoint," Energy in the News, special supplement, New York Mercantile Exchange, New York, N.Y., pp. 14-15, spring.

Energy in the News, 1991, special supplement, New York Mercantile Exchange, New York, N.Y., p. 35, spring.

Hatcher, D.B., and A.R. Tussing, 1992, State Regulatory Challenges for the Natural Gas Industry in the 1990s and Beyond, NRRI 92-10, The National Regulatory Research Institute, Columbus, Ohio, June.

Henderson, J.M., and R. Quandt, 1980, Microeconomic Theory: A Mathematical Theory, 3rd ed., McGraw-Hill Book Co., New York, N.Y.

Hoffman, P., 1991, "Carriage through the First Half of 1991," Issue Analysis Report No. 91-5, Interstate Natural Gas Association of America, Washington, D.C., Nov.

Hull, J., 1989, Options, Futures, and Other Derivative Securities, Prentice-Hall International Inc., Englewood Cliffs, N.J. 
Joskow, P.L., 1987, "Contract Duration and Relation-Specific Investments: Empirical Evidence from the Coal Market," American Economic Review 77(1):168-185, March.

Joskow, P.L., 1988, "Price Adjustment in Long-Term Contracts: The Case of Coal," Journal of Law and Economics XXXI:47-83, April.

Kalt, J.P., and F.C. Schuller, 1987, Deregulating the Natural Gas Industry, Quorum Books, New York, N.Y.

Kolb, R.W., 1991, Understanding Futures Markets, Institute of Finance, New York, N.Y.

Lemon, J.R., 1986, "Gas Supply and Transmission Capacity Contracting by Local Distribution Companies," in Natural Gas Industry Restructuring Issues, The National Regulatory Institute, Columbus, Ohio, pp. 91-135.

Lemon, J.R., 1990, "Price vs. Risk under Levels of Open-Access, Natural Gas, pp. 8-11, July.

Lucas, D.A., 1991, "Canadian Natural Gas: Uncertain Future," in The New World: Natural Gas and Electric Power, Cambridge Energy Forum, Cambridge Energy Research Associates, pp. 18-25.

Marshall, J., 1992, "Critics Say PG\&E Overpaid Canadian Gas Suppliers," San Francisco Chronicle, Jan. 24.

Mitchell, J.S., 1991, "Natural Gas Futures: The First Year," Energy in the News, special supplement, New York Mercantile Exchange, New York, N.Y., p. 1, spring.

Mulherin, J.H., 1986, "Complexity in Long Term Contracts: An Analysis of Natural Gas Contractual Provisions," Journal of Law, Economics, and Organization 2(1):105-117, spring.

NPC, 1989, System Dynamics: Petroleum Storage and Transportation, report in vol. 5 of a series of reports, National Petroleum Council, Washington, D.C., April.

Palmer, K.P., et al., 1993, "Electricity Fuel Contracting: Relationships With Coal and Gas Suppliers," Energy Policy, Vol. 21, No. 10, pp. 1045-54.

Polinsky, A.M., 1987, "Fixed Price versus Spot Price Contracts: A Study of Risk Allocation," Journal of Law, Economics and Organization 3(1):27-46, spring.

Public Utilities Fortnightly, 1990, "Question II: Gas Procurement Strategy," pp. 49-59, Oct. 25.

Roeber, J., 1990, "The Impact of Futures on Energy Markets," in J.E. Treat (editor), Energy Futures: Trading Opportunities for the 1990s, Pennwell Books, Tulsa, Okla., pp. 307-332.

Schlesinger, B., 1990, "Natural Gas Trading and Futures," in J.E. Treat (editor), Energy Futures: Trading Opportunities for the 1990s, Pennwell Books, Tulsa, Okla., pp. 31-44. 
Schlesinger, B., 1991, "Spot Trading, Futures, and Long-Term Contracts: Gas Market Mechanisms in the 1990s," Energy in the News, New York Mercantile Exchange, New York, N.Y., pp. 2-6, spring.

Sutherland, R.J., 1990, "Economic Efficiency in the Emerging Market for Independently Produced Power," Energy Systems and Policy 14:167-181.

Sutherland, R.J., 1993, "Natural Gas Contracts in an Emerging Competitive Market" Energy Policy, 21:1191-1204.

U.S. Department of Energy, 1989, Growth in Unbundled Natural Gas Transportation Services: 1982-1987, DOE/EIA-0525, Energy Information Administration, Washington, D.C.

U.S. Department of Energy, 1991a, Annual Energy Review, 1990, DOE/EIA-0384(90), Energy Information Administration, Washington, D.C.

U.S. Department of Energy, 1991b, Trends in Contract Coal Transportation, 1979-1987, DOE/ELA-0549, Energy Information Administration, Washington, D.C., Sept.

U.S. Department of Energy, 1994, The Domestic Natural Gas and Oil Initiative, Washington, D.C.

Verleger, P.K., 1988, "The Role and Impact of Commodity Market Institutions in the Determination of Oil Prices," Annual Energy Review 13:359-382.

Wielgus, P.J., 1992, "Comments of Enron Gas Services," testimony before the Public Utilities Commission of the State of California, Feb.

Williamson, O.E. 1979, "Transaction-Cost Economics: 'The Governance of Contractual Relations," Journal of Law and Economics 22:233-261.

Williamson, O.E., 1983, "Credible Commitments: Using Hostages to Support Exchange," The American Economic Review, 73:519-540, Sept.

Williamson, O.E., 1985, The Economic Institutions of Capitalism, The Free Press, New York, N.Y. 